\title{
Notes for genera update - Ascomycota: 6616-6821
}

\section{Wijayawardene $\mathrm{NN}^{1,2}$, Hyde $\mathrm{KD}^{2}$, Divakar $\mathrm{PK}^{3}$, Rajeshkumar $\mathrm{KC}^{4}$, Weerahewa $D^{5}$, Delgado $G^{6}$, Wang $Y^{7}$, Fu $L^{1 *}$}

${ }^{1}$ Shandong Institute of Pomologe, Taian, Shandong Province, 271000, China

${ }^{2}$ Center of Excellence in Fungal Research, Mae Fah Luang University, Chiang Rai, 57100, Thailand

${ }^{3}$ Departamento de Biologl 'a Vegetal II, Facultad de Farmacia, Universidad Complutense de Madrid, 28040 Madrid, Spain

${ }^{4}$ National Fungal Culture Collection of India (NFCCI), Biodiversity and Palaeobiology (Fungi) Group, Agharkar Research Institute, Pune, Maharashtra 411 004, India

${ }^{5}$ Department of Botany, The Open University of Sri Lanka, Nawala, Nugegoda, Sri Lanka

${ }^{6} 10900$ Brittmoore Park Drive Suite G Houston, TX 77041

${ }^{7}$ Department of Plant Pathology, Agriculture College, Guizhou University, Guiyang 550025, People's Republic of China

Wijayawardene NN, Hyde KD, Divakar PK, Rajeshkumar KC, Weerahewa D, Delgado G, Wang Y, Fu L 2018 - Notes for genera update - Ascomycota: 6616-6821. Mycosphere 9(1), 115-140, Doi 10.5943/mycosphere/9/1/2

\begin{abstract}
Taxonomic knowledge of the Ascomycota, is rapidly changing because of use of molecular data, thus continuous updates of existing taxonomic data with new data is essential. In the current paper, we compile existing data of several genera missing from the recently published "Notes for genera-Ascomycota". This includes 206 entries.
\end{abstract}

Key words - Asexual genera - Data bases - Sexual genera - Taxonomy

\section{Introduction}

Maintaining updated databases and checklists of genera of fungi is an important and essential task, as it is the base of all taxonomic studies. Outlines of Ascomycota and asexual fungi (Lumbsch \& Huhndorf 2010, Hyde et al. 2011, Wijayawardene et al. 2012, 2017b, Kirk et al. 2013, Hongsanan et al. 2017, Hyde et al. 2017, Jaklitsch et al. 2016, Ekanayaka et al. 2017, Liu et al. 2017, Lücking et al. 2017), are some of the efforts that have been published to compile all existing data. The recent work by Wijayawardene et al. (2017a) compiled the genera of Ascomycota into a single manuscript; Notes for genera: Ascomycota. This project was carried out with the involvement of more than 90 mycologists who are experts in different fields of mycology, including lichens.

Most recent taxonomic studies have relied on Kirk et al. $(2008,2013)$ and Index Fungorum (2018), but these lack the numerous recent nomenclatural and taxonomic changes that have occurred in the publications of Hyde et al. (2013), Wijayawardene et al. (2014), Senanayake et al. (2015), Maharachchikumbura et al. $(2015,2016)$ and others. Kirk et al. (2013) provided a list of 'a without-prejudice list of generic names' based on genera published prior to 2000 and lacked recently resurrected genera. 
Thus, in the current paper, we compile notes on the genera missing in Wijayawardene et al. (2017) and provide extra entries. Moreover, corrected entries are provided for Nephromopsis Müll. Arg. 1891 and Cetraria Ach. 1803.

\section{Materials \& Methods}

The list of genera was extracted from Kirk et al. (2008, 2013), Index Fungorum (2017) and Wijayawardene et al. (2017a) and cross checked against Lumbsch \& Huhndorf (2010), Hyde et al. (2011), Seifert et al. (2011) and Wijayawardene et al. (2012, 2017b, c) for missing genera.

\section{Results}

In this section, we provide the entries for genera.

Acarocybella M.B. Ellis 1960, Ascomycota genera incertae sedis, one species, type: A. jasminicola M.B. Ellis, hyphomycetous, saprobes, terrestrial, Africa, Caribbean, see Seifert et al. (2011; morphology), Wijayawardene et al. (2012, 2017b, c; outline), Kirk et al. (2013; genus accepted), cultures and sequences are unavailable.

Aegeanispora Jones \& Abdel-Wahab 2017, Pleosporales genera incertae sedis, Dothideomycetes, one species, type: A. elanii Jones \& Abdel-Wahab, coelomycetous, sexual morph unknown, saprobes, marine, Turkey, see Abdel-Wahab et al. (2017; phylogeny), Wijayawardene et al. (2017b, c; outline), cultures and sequences are available.

Aenigmatospora R.F. Castañeda, Saikawa, Guarro \& M. Calduch 1999, Ascomycota genera incertae sedis, one species, type: A. pulchra R.F. Castañeda, Saikawa, Decock, Guarro \& M. Calduch, ?hyphomycetous, saprobes, terrestrial, Cuba, see Seifert et al. (2011; not confirmed as hyphomycetous), Wijayawardene et al. (2012, 2017b, c; outline), Kirk et al. (2013; genus accepted), cultures and sequences are unavailable.

Allocucurbitaria Valenzuela-Lopez, Stchigel, Guarro \& Cano 2017, Cucurbitariaceae, Pleosporales, Dothideomycetes, two species, type: A. botulispora Valenzuela-Lopez, Stchigel, Guarro \& Cano, coelomycetous, from human scab, USA, see Valenzuela-Lopez et al. (2017; morphology, phylogeny), Wijayawardene et al. (2017; outline), cultures and sequences are available.

Allothyriella Bat., Cif. \& Nascim. 1959, Ascomycota genera incertae sedis, one species, type: A. marcgraviae Bat., Cif. \& Nascim., coelomycetous, saprobes, terrestrial, Ecuador, Wijayawardene et al. (2012, 2017b, c; outline), Kirk et al. (2013; genus accepted), cultures and sequences are unavailable.

Alpinaria Jaklitsch \& Voglmayr 2017, Melanommataceae, Pleosporales, Dothideomycetes, one species, type: A. rhododendri (Niessl) Jaklitsch \& Voglmayr, asexual morph unknown, saprobes, terrestrial, Europe, see Jaklitsch \& Voglmayr (2017; taxonomy, phylogeny), Wijayawardene et al. (2017b, c; outline), cultures and sequences are available.

Amerosporium Speg. Ascomycota genera incertae sedis, three species, type: A. polynematoides Speg., coelomycetous, sexual morph unknown, saprobes, terrestrial, cosmopolitan, see Wijayawardene et al. (2016; taxonomy, accepted as Sclerotiniaceae), cultures and sequences are unavailable.

Amesia X. Wei Wang, Samson \& Crous 2016, Chaetomiaceae, Sordariales, Sordariomycetes, four species, type: A. atrobrunnea (L.M. Ames) X. Wei Wang \& Samson, asexual morph unknown, 
indoor fungus, cosmopolitan, see Wang et al. (2016; taxonomy, phylogeny), Wijayawardene et al. (2017b, c; outline), sequences are available.

Amphophialis R.F. Castañeda, W.B. Kendr. \& Guarro 1998, Ascomycota genera incertae sedis, one species, type: A. concinna R.F. Castañeda, W.B. Kendr. \& Guarro, hyphomycetous, saprobes, terrestrial, Caribbean, see Seifert et al. (2011; morphology), Wijayawardene et al. (2012, 2017b, c; outline), Kirk et al. (2013; genus accepted), cultures and sequences are unavailable.

Ampullifera Deighton 1960, Dothideomycetes, genera incertae sedis, one species, type: A. foliicola Deighton, hyphomycetous, sexual morph unknown, lichenicolous, terrestrial, North America, see Seifert et al. (2011; treated as a distinct genus), Kirk et al. (2013; genus accepted), Wijayawardene et al. (2017c; outline), cultures and sequences are available.

Ancoraspora Mig. Rodr. (1982) [1981], one species, type: A. cubensis Mig. Rodr., one species, coelomycetous, sexual morph unknown, South America, see Seifert et al. (2011; morphology), Wijayawardene et al. (2012, 2017b; outline), Kirk et al. (2013; genus accepted), cultures and sequences are unavailable.

Ancorasporella J. Mena, Mercado \& Heredia 2017, Ascomycota genera incertae sedis, one species, type: A. mexicana J. Mena, Mercado \& Heredia, coelomycetous, sexual morph unknown, saprobes, terrestrial, South America, see Index Fungorum (2017; validation), cultures and sequences are unavailable.

Apiosporium Kunze 1817, Ascomycota genera incertae sedis, one species, type: A. concinna R.F. Castañeda, W.B. Kendr. \& Guarro, coelomycetous, saprobes, terrestrial, cosmopolitan, see Wijayawardene et al. (2012, 2017b, c; outline), Kirk et al. (2013; not listed), cultures and sequences are unavailable.

Arcopilus X. Wei Wang, Samson \& Crous 2016, Chaetomiaceae, Sordariales, Sordariomycetes, five species, type: A. aureus (Chivers) X. Wei Wang \& Samson, asexual morph unknown, indoor fungus, cosmopolitan, see Wang et al. (2016; taxonomy, phylogeny), Wijayawardene et al. (2017c; outline), sequences are available.

Ardhachandra Subram. \& Sudha 1978, Ascomycota genera incertae sedis, five species, type: A. selenoides (de Hoog) Subram. \& Sudha, coelomycetous, saprobes, terrestrial, Africa, Asia, South America, see Mel'nik (2012; new species), Wijayawardene et al. (2012, 2017b, c; outline), Kirk et al. (2013; not listed), Rashmi (2014; new records), cultures and sequences are unavailable.

Arthropycnis Constant. 1992, Ascomycota genera incertae sedis, one species, type: A. praetermissa Constant, one species, coelomycetous, sexual morph unknown, worldwide, see Kirk et al. (2008; mentioned Rhynchostoma P. Karst. as the sexual morph), Wijayawardene et al. (2012, 2017b; outline), Kirk et al. (2013; genus accepted), cultures and sequences are unavailable.

Ascosubramania Rajendran 1997, Ascomycota genera incertae sedis, one species, type: A. melanographoides Rajendran, asexual morph hyphomycetous, terrestrial, India, see Lumbsch \& Huhndorf (2010; outline), Wijayawardene et al. (2017c; outline), sequences are unavailable.

Aspiciliella M. Choisy 1932, Megasporaceae, Pertusariales, Lecanoromycetes, three species type: A. intermutans (Nyl.) M.Choisy, lichenized, see Werner (1932, taxonomy), Zakeri et al. (2017; taxonomy, phylogeny), sequences are available 
Astelechia Cif. 1962, Ascomycota genera incertae sedis, two species, type: A. radians Cif., coelomycetous, saprobes, terrestrial, Dominican Republic, see Wijayawardene et al. (2012, 2017b, c; outline), Kirk et al. (2013; genus accepted), cultures and sequences are unavailable.

Australosphaerella Videira \& Crous 2017, Mycosphaerellaceae, Capnodiales, Dothideomycetes, one species, type: A. nootherensis (Carnegie) Videira \& Crous, asexual morph unknown, on living leaves, terrestrial, Australia, see Videira et al. (2017; taxonomy, phylogeny), Wijayawardene et al. (2017c; outline), cultures and sequences are available.

Austromelanelixia Divakar, Crespo \& Lumbsch 2017, Parmeliaceae, Lecanorales, Lecanoromycetes, five species, type: A. stracheyi piliferella (Essl.) Divakar, Crespo \& Lumbsch (C. Bab.), lichenized, southern Hemisphere, see Divakar et al. (2017; taxonomy, phylogeny), sequences are available.

Bahugada K.A. Reddy \& V. Rao 1984, Ascomycota genera incertae sedis, one species, type: B. sundara K.A. Reddy \& V. Rao, hyphomycetous, saprobes, terrestrial, Asia, see Seifert et al. (2011; morphology), Wijayawardene et al. (2012, 2017b, c; outline), Kirk et al. (2013; genus not listed), cultures and sequences are unavailable.

Berggrenia Cooke 1879, Ascomycota, genera incertae sedis, one species, type: B. aurantiaca Cooke, asexual morph unknown, terrestrial, New Zealand, see Lumbsch \& Huhndorf (2010; outline), Wijayawardene et al. (2017c; outline), sequences are unavailable.

Brencklea Petr. 1923, Ascomycota genera incertae sedis, one species, type: B. sisyrinchii (Ellis \& Everh.) Petr., coelomycetous, saprobes, terrestrial, Asia, see Kirk et al. (2008; treated as a synonym of Scolecosporiella), Wijayawardene et al. (2012, 2016, 2017b, c; outline, taxonomy), Kirk et al. (2013; genus not listed), cultures and sequences are unavailable.

Briansuttonia R.F. Castañeda, Minter \& Saikawa 2004, Ascomycota genera incertae sedis, one species, type: B. alternarioides (B. Sutton \& Pascoe) R.F. Castañeda, Minter \& Saikawa, hyphomycetous, sexual morph unknown, saprobes, terrestrial, Australasia, see Seifert et al. (2011; morphology), Wijayawardene et al. (2014, 2017b, c; outline), cultures and sequences are unavailable.

Brunswicksiella Videira \& Crous 2017, Mycosphaerellaceae, Capnodiales, Dothideomycetes, one species, type: B. parsonsiae (Crous \& Summerell) Videira \& Crous, asexual morph coelomycetous, pathogens, terrestrial, Australia, see Videira et al. (2017; taxonomy, phylogeny), Wijayawardene et al. (2017c; outline), cultures and sequences are available.

Bryophytomyces Cif. 1953, Ascomycota genera incertae sedis, one species, type: B. sphagni (Navashin) Cif., hyphomycetous, saprobes, terrestrial, cosmopolitan, see Seifert et al. (2011; notes), Wijayawardene et al. (2012, 2017b, c; outline), Kirk et al. (2013; not listed), cultures and sequences are unavailable.

Calcarisporiella de Hoog 1974, Ascomycota genera incertae sedis, one species, type: C. thermophila (H.C. Evans) de Hoog, hyphomycetous, on coral, marine, Europe, see Seifert et al. (2011; morphology), Wijayawardene et al. (2012, 2017b, c; outline), Kirk et al. (2013; genus accepted), cultures and sequences are unavailable.

Calocline Syd. 1939, Ascomycota genera incertae sedis, one species, type: C. chusqueae Syd., coelomycetous, saprobes, terrestrial, Ecuador, see Wijayawardene et al. (2012, 2017b, c; outline), Kirk et al. (2013; genus accepted), cultures and sequences are unavailable. 
Camarosporidiella Wanas., Wijayaw., K.D. Hyde 2017, Camarosporidiellaceae, Pleosporales, Dothideomycetes, 20 species, type: C. caraganicola (Phukhams., Bulgakov \& K.D. Hyde) Phukhams., Wanas. \& K.D. Hyde, coelomycetous, saprobes, terrestrial, cosmopolitan, see Wanasinghe et al. (2017; outline), Kirk et al. (2013; genus accepted), cultures and sequences are unavailable.

Catenophora Luttr. 1940, Ascomycota genera incertae sedis, three species, type: C. pruni Luttr., coelomycetous, saprobes, terrestrial, USA, see Wijayawardene et al. (2012, 2017b, c; outline, Kirk et al. (2013; not listed), cultures and sequences are unavailable.

Catenulaster Bat. \& C.A.A. Costa 1959, Ascomycota genera incertae sedis, three species, type: $C$. anacardiicola Bat. \& C.A.A. Costa, coelomycetous, saprobes, terrestrial, Brazil, see Wijayawardene et al. (2012, 2017b, c; outline), Kirk et al. (2013; genus accepted), cultures and sequences are unavailable.

Catenulocercospora C. Nakash., Videira \& Crous 2017, Mycosphaerellaceae, Capnodiales, Dothideomycetes, one species, type: C. fusimaculans (G.F. Atk.) C. Nakash., Videira \& Crous, coelomycetous, sexual morph unknown, pathogens, terrestrial, Thailand, see Videira et al. (2017; taxonomy, phylogeny), Wijayawardene et al. (2017c; outline), cultures and sequences are available.

Celosporium Tsuneda \& M.L. Davey 2010, Dothideales, genera incertae sedis, Dothideomycetes, one species, type: T. laricicola Tsuneda \& M.L. Davey, hyphomycetous, sexual morph unknown, saprobes, terrestrial, Alberta, see Tsuneda et al. (2010; taxonomy), Thambugala et al. (2014; taxonomy, phylogeny), Wijayawardene et al. (2014, 2017c; outline), holotype of the type: UAMH 11008 .

Cercoramularia Videira, H.D. Shin, C. Nakash. \& Crous 2017, Mycosphaerellaceae, Capnodiales, Dothideomycetes, one species, type: C. koreana Videira, H.D. Shin, C. Nakash. \& Crous, hyphomycetous, sexual morph unknown, pathogens, terrestrial, Republic of Korea, see, Videira et al. (2017; taxonomy, phylogeny), Wijayawardene et al. (2017c; outline), cultures and sequences are available.

Cercosphaerella Kleb. 1918, Mycosphaerellaceae, Capnodiales, Dothideomycetes, two species, type: C. millegrana (Cooke) Kleb., asexual morph hyphomycetous, pathogens, terrestrial, cosmopolitan, see Videira et al. (2017; reinstated the genus and provisionally placed in Mycosphaerellaceae pending further phylogenetic analyses), Wijayawardene et al. (2017c; outline), cultures and sequences are unavailable.

Cetraria Ach. 1803 nom. cons. (= Allocetraria Kurok. \& M.Y. Lai 1991; = Cetrariomyces E.A. Thomas 1939; = Cetrariella Ka"rnefelt \& A. Thell, 1993; = Coelocaulon Link 1833; = Geissodea Vent. 1799; = Platisma Hoffm. 1796 [1795]; = Platyphyllum Vent. 1799; = Pseudocornicularia Gyeln. 1933; = Squamaria Hoffm. 1789 [1790] = Usnocetraria M.J. Lai \& J.C. Wei 2007; = Vulpicida J.-E. Mattsson \& M.J. Lai 1993; Allocetraria Kurok. \& M.Y. Lai 1991 fide Divakar et al. 2017; Species Fungorum 2017), Parmeliaceae, Lecanorales, Lecanoromycetes, 35 species, type: $C$. islandica (L.) Ach., asexual morph unknown, epiphytic or saxicolous, widespread, see Thell et al. (2009; taxonomy), Lumbsch \& Huhndorf (2010; outline), Kirk et al. (2013; genus accepted), Miadlikowska et al. (2014; phylogeny), Lücking et al. (2017; classification), Divakar et al. (2017; phylogeny), sequences are available.

Cheiromoniliophora Tzean \& J.L. Chen 1990, Pleosporales genera incertae sedis, Dothideomycetes, one species, type: B. elegans Tzean \& J.L. Chen, hyphomycetous, sexual morph unknown, terrestrial, Asia, South America, see Seifert et al. (2011; morphology), Kirschner et al. 
(2013; transferred type species to Pseudodictyosporium), Wijayawardene et al. (2014, 2017b, c; outline), cultures and sequences are unavailable.

Cheiromyces Berk. \& M.A. Curtis 1857, Ascomycota genera incertae sedis, three species, type: $C$. anacardiicola Bat. \& C.A.A. Costa, hyphomycetous, saprobes, terrestrial, cosmopolitan, see Seifert et al. (2011; morphology), Wijayawardene et al. (2012, 2017b, c; outline, taxonomy), Kirk et al. (2013; genus accepted), cultures and sequences are unavailable.

Chromelosporium Corda 1833, Pezizaceae, Pezizales, Pezizomycetes, c. ten species, type: C. ochraceum Corda, hyphomycetous, saprobes, in soil, Europe, North America, see Seifert et al. (2011; morphology), Wijayawardene et al. (2012, 2017b, c; outline), Kirk et al. (2013; not listed), cultures and sequences are available.

Chromosporium Corda 1829, Ascomycota genera incertae sedis, three species, type: $C$. anacardiicola Bat. \& C.A.A. Costa, hyphomycetous, saprobes, terrestrial, cosmopolitan, see Seifert et al. (2011; morphology), Wijayawardene et al. (2012, 2017b, c; outline), Kirk et al. (2013; genus accepted), cultures and sequences are unavailable.

Chryseidea Onofri 1981, Ascomycota genera incertae sedis, one species, type: C. africana Onofri, hyphomycetous, saprobes, terrestrial, Africa, see Seifert et al. (2011; morphology), Wijayawardene et al. (2012, 2017b, c; outline), Kirk et al. (2013; genus accepted), cultures and sequences are unavailable.

Chuppomyces Videira \& Crous 2017, Mycosphaerellaceae, Capnodiales, Dothideomycetes, one species, type: C. handelii (Bubák) U. Braun, C. Nakash., Videira \& Crous, hyphomycetous, sexual morph unknown, pathogens, terrestrial, Netherlands, Turkey, see Videira et al. (2017; taxonomy, phylogeny), Wijayawardene et al. (2017c; outline), cultures and sequences are available.

Ciferrioxyphium Bat. \& H. Maia 1963, Ascomycota genera incertae sedis, one species, type: $C$. giganteum Bat. \& H. Maia, hyphomycetous, saprobes, terrestrial, cosmopolitan, see Seifert et al. (2011; morphology), Wijayawardene et al. (2012, 2017b, c; outline), Kirk et al. (2013; genus accepted), cultures and sequences are unavailable.

Clarohilum Videira \& Crous 2017, Mycosphaerellaceae, Capnodiales, Dothideomycetes, one species, type: $C$. henningsii (Allesch.) Videira \& Crous, asexual morph hyphomycetous, pathogens, terrestrial, Laos, Tanzania, see Videira et al. (2017; taxonomy, phylogeny), Wijayawardene et al. (2017c; outline), cultures and sequences are available.

Clavariopsis De Wild. 1895, Dothideomycetes, genera incertae sedis, one species, type: $C$. aquatica De Wild., hyphomycetous, sexual morph unknown, on leaves, in water, terrestrial/ aquatic, cosmopolitan, see Seifert et al. (2011; treated as a distinct genus), Kirk et al. (2013; genus accepted), Wijayawardene et al. (2017c; outline), cultures and sequences are available.

Collariella X. Wei Wang, Samson \& Crous 2016, Chaetomiaceae, Sordariales, Sordariomycetes, five species, type: C. bostrychodes (Zopf) X. Wei Wang \& Samson, asexual morph unknown, indoor fungus, cosmopolitan, see Wang et al. (2016; taxonomy, phylogeny), Wijayawardene et al. (2017c; outline), sequences are available.

Collarispora Videira \& Crous 2017, Mycosphaerellaceae, Capnodiales, Dothideomycetes, one species, type: C. valgourgensis (Crous) Videira \& Crous, asexual morph hyphomycetous, pathogens, terrestrial, France, USA, see Videira et al. (2017; taxonomy, phylogeny), Wijayawardene et al. (2017c; outline), cultures and sequences are available. 
Coremiopassalora U. Braun, C. Nakash., Videira \& Crous 2017, Mycosphaerellaceae, Capnodiales, Dothideomycetes, two species, type: C. eucalypti (Crous \& Alfenas) U. Braun, C. Nakash., Videira \& Crous, hyphomycetous, pathogens, terrestrial, Brazil, see Videira et al. (2017; taxonomy, phylogeny), Wijayawardene et al. (2017c; outline), cultures and sequences are available.

Corinectria González \& P. Chaverri 2017, Nectriaceae, Hypocreales, Sordariomycetes, three species, type: C. fuckeliana (C. Booth) C. González \& P. Chaverri, asexual morph hyphomycetous, saprobes, aquatic, cosmopolitan, see González \& Chaverri (2017; taxonomy), Wijayawardene et al. (2017c; outline), cultures and sequences are available.

Cubonia Sacc. 1889, Ascobolaceae, Pezizales, Pezizomycetes, three species, type: C. brachyasca (Marchal) Sacc., saprobes, cosmopolitan, see Lumbsch \& Huhndorf (2010; outline), Wijayawardene et al. (2012, 2017b, c; outline), cultures and sequences are unavailable.

Cumuliphoma Valenzuela-Lopez, Stchigel, Crous, Guarro \& Cano 2017, Didymellaceae, Pleosporales, Dothideomycetes, three species, type: C. omnivirens (Aveskamp et al.) ValenzuelaLopez, Stchigel, Crous, Guarro \& Cano, coelomycetous, saprobes or pathogens, cosmopolitan, see Valenzuela-Lopez et al. (2017; morphology, phylogeny), Wijayawardene et al. (2017; outline), cultures and sequences are available.

Curviclavula G. Delgado, A.N. Mill. \& F.A. Fernández 2015, Hyaloscyphaceae, Helotiales, Leotiomycetes, one species, type: C. anemophila G. Delgado, A.N. Mill. \& F.A. Fernández, hyphomycetous, from air particles, USA, see Delgado et al. (2015; taxonomy, phylogeny), Wijayawardene et al. (2017c; outline), cultures and sequences are available.

Dactuliophora C.L. Leakey 1964, Dothideomycetes, genera incertae sedis, five species, type: $C$. tarrii C.L. Leakey, hyphomycetous, sexual morph unknown, on leaves, in water, terrestrial/ aquatic, cosmopolitan, see Seifert et al. (2011; treated as a distinct genus), Kirk et al. (2013; genus accepted), Wijayawardene et al. (2017c; outline), cultures and sequences are available.

Deightonomyces Videira \& Crous 2017, Mycosphaerellaceae, Capnodiales, Dothideomycetes, one species, type: D. perplexa (Beilharz et al.) Videira \& Crous, hyphomycetous, pathogens, terrestrial, Indonesia, see Videira et al. (2017; taxonomy, phylogeny), Wijayawardene et al. (2017c; outline), cultures and sequences are available.

Dendrographiella Agnihothr. 1972, Ascomycota genera incertae sedis, one species, type: D. podosporioides Agnihothr., hyphomycetous, saprobes, terrestrial, Asia, see Seifert et al. (2011; morphology), Wijayawardene et al. (2012, 2017b, c; outline), Kirk et al. (2013; genus accepted), cultures and sequences are unavailable.

Dendrographium Massee 1892, Ascomycota genera incertae sedis, five species, type: $D$. atrum Massee, hyphomycetous, saprobes, terrestrial, Pantropical, see Seifert et al. (2011; morphology), Wijayawardene et al. (2012, 2017b, c; outline), Kirk et al. (2013; genus accepted), cultures and sequences are unavailable.

Dendroseptoria Alcalde 1948, Stictidaceae, Ostropales, Lecanoromycetes, three species, type: D. arrhenatheri Alcalde, saprobes, Europe, see Koukol et al. (2017; DNA), Wijayawardene et al. (2017c; outline), cultures and sequences are available.

Devonomyces Videira \& Crous 2017, Mycosphaerellaceae, Capnodiales, Dothideomycetes, one species, type: D. endophyticus (Crous \& H. Sm. Ter) Videira \& Crous, asexual morph 
hyphomycetous, pathogens, terrestrial, Australia, South Africa, see Videira et al. (2017; taxonomy, phylogeny), Wijayawardene et al. (2017c; outline), cultures and sequences are available.

Dichotomopilus X. Wei Wang, Samson \& Crous 2016, Chaetomiaceae, Sordariales, Sordariomycetes, seven species, type: D. indicus (Corda) X. Wei Wang \& Samson, asexual morph unknown, indoor fungus, cosmopolitan, see Wang et al. (2016; taxonomy, phylogeny), Wijayawardene et al. (2017c; outline), sequences are available.

Didymopsis Sacc. \& Marchal 1885, Ascomycota genera incertae sedis, three species, type: D. perexigua Sacc. \& Marchal, hyphomycetous, saprobes, terrestrial, Europe, see Seifert et al. (2011; morphology), Wijayawardene et al. (2012, 2017b, c; outline), Kirk et al. (2013; genus accepted), cultures and sequences are unavailable.

Distocercosporaster Videira, H.D. Shin, C. Nakash. \& Crous 2017, Mycosphaerellaceae, Capnodiales, Dothideomycetes, two species, type: D. dioscoreae (Ellis \& G. Martin) Videira, H.D. Shin, C. Nakash. \& Crous, hyphomycetous, pathogens, terrestrial, Republic of Korea, see Videira et al. (2017; taxonomy, phylogeny), Wijayawardene et al. (2017c; outline), cultures and sequences are available.

Distomycovellosiella U. Braun, C. Nakash., Videira \& Crous 2017, Mycosphaerellaceae, Capnodiales, Dothideomycetes, one species, type: D. brachycarpa (Syd.) U. Braun, C. Nakash., Videira \& Crous, hyphomycetous, pathogens, terrestrial, cosmopolitan, see Videira et al. (2017; taxonomy, phylogeny), Wijayawardene et al. (2017c; outline), cultures and sequences are available.

Ditangifibula G.C. Adams 1995, Ascomycota genera incertae sedis, one species, type: D. dikaryotae G.C. Adams, hyphomycetous, saprobes, terrestrial, North America, see Seifert et al. (2011; morphology), Wijayawardene et al. (2012, 2017b, c; outline), Kirk et al. (2013; genus accepted), cultures and sequences are unavailable.

Dokmaia Promp. 2003, Pleosporineae genera incertae sedis, Dothideomycetes, one species, type: D. monthadangi Promp., hyphomycetous, sexual morph unknown, terrestrial, Asia, see Seifert et al. (2011; morphology), Luo et al. (2014a; DNA), Wijayawardene et al. (2014, 2017c; outline), cultures and sequences are available.

Drepanospora Berk. \& M.A. Curtis 1875, Ascomycota genera incertae sedis, two species, type: $D$. pannosa Berk. \& M.A. Curtis, hyphomycetous, saprobes, terrestrial, cosmopolitan, see Seifert et al. (2011; morphology), Wijayawardene et al. (2012, 2017b, c; outline), Kirk et al. (2013; not listed), cultures and sequences are unavailable.

Ectophoma Valenzuela-Lopez, Cano, Crous, Guarro \& Stchigel 2017, Didymellaceae, Pleosporales, Dothideomycetes, two species, type: E. multirostrata (P.N. Mathur et al.) Valenzuela-Lopez, Cano, Crous, Guarro \& Stchigel., coelomycetous, saprobes or pathogens, India, The Netherlands, see Valenzuela-Lopez et al. (2017; morphology, phylogeny), Wijayawardene et al. (2017c; outline), cultures and sequences are available.

Elegantimyces Goh, K.M. Tsui \& K.D. Hyde 1998, Ascomycota genera incertae sedis, one species, type: E. sporidesmiopsis Goh, K.M. Tsui \& K.D. Hyde, hyphomycetous, saprobes, aquatic, Asia, see Seifert et al. (2011; morphology), Wijayawardene et al. (2012, 2017b, c; outline), Kirk et al. (2013; not listed), cultures and sequences are unavailable.

Endosporium Tsuneda 2008, Dothideomycetes, genera incertae sedis, five species, type: E. populitremuloides Tsuneda, hyphomycetous, sexual morph unknown, on bird skin and trees, terrestrial, 
North America, see Tsuneda et al. (2008; treated as Myriangiales), Seifert et al. (2011; morphology, treated as Myriangiales), Wijayawardene et al. (2014, 2017c; outline, treated as Dothideomycetes), cultures and sequences are available.

Entalbostroma J.D. Rogers \& P.R. Johnst. 2016, Xylariaceae, Xylariales, Sordariomycetes, two species, type: E. erumpens J.D. Rogers \& P.R. Johnst., asexual morph hyphomycetous, indoor fungus, New Zealand, see Johnston et al. (2016; taxonomy, phylogeny), Wijayawardene et al. (2017c; outline), sequences are available.

Entosordaria (Sacc.) Höhn. 1920, Barrmaeliaceae, Xylariales, Sordariomycetes, two species, type: E. perfidiosa (De Not.) Höhn., asexual morph hyphomycetous, saprobes, New Zealand, see Voglmayr et al. (2017; resurrected the genus, phylogeny), Wijayawardene et al. (2017c; outline), sequences are available.

Exopassalora Videira \& Crous 2017, Phaeothecoidiellaceae, Capnodiales, Dothideomycetes, one species, type: E. zambiae (Crous \& T.A. Cout.) Videira \& Crous, hyphomycetous, pathogens, terrestrial, Indonesia, see Videira et al. (2017; taxonomy, phylogeny), Wijayawardene et al. (2017c; outline), cultures and sequences are available.

Exutisphaerella Videira \& Crous 2017, Mycosphaerellaceae, Capnodiales, Dothideomycetes, one species, type: E. laricina Videira \& Crous, asexual morph coelomycetous, pathogens, terrestrial, Switzerland, see Videira et al. (2017; taxonomy, phylogeny), Wijayawardene et al. (2017c; outline), cultures and sequences are available.

Falciphoriella Hern.-Restr. \& Crous 2016, Magnaporthaceae, Magnaporthales, Sordariomycetes, one species, type: F. solaniterrestris Hern.-Restr. \& Crous, hyphomycetous, saprobes, Netherlands, see Hernández-Restrepo et al. et al. (2016; taxonomy, phylogeny), Wijayawardene et al. (2017c; outline), cultures and sequences are available.

Foliophoma Crous 2017, Coniothyriaceae, Pleosporales, Dothideomycetes, one species, type: F. fallens (Saccardo) Crous, coelomycetous, plant pathogen, Italy, New Zealand, see Crous \& Groenewald (2017; taxonomy and phylogeny), Papizadeh et al. (2017; phylogeny), Wanasinghe et al. (2017; classification), cultures and sequences are available.

Fusculina Crous \& Summerell 2006, Pleosporales, genera incertae sedis, Dothideomycetes, one species, type: F. eucalypti Crous \& Summerell, coelomycetous, sexual morph unknown, pathogens, terrestrial, Australia, see Wijayawardene et al. (2014, 2017c; outline), holotype and ex-type of the type: CBS H-19747, CPC 12946.

Fusicladosporium Partr. \& Morgan-Jones 2003, Ascomycota genera incertae sedis, three species, type: F. carpophilum (Thüm.) Partr. \& Morgan-Jones., hyphomycetous, sexual morph unknown, saprobes, terrestrial, cosmopolitan, see Kirk et al. (2008; treated as a synonym of Fusicladium Bonord.), Seifert et al. (2011; treated as a distinct genus), Wijayawardene et al. (2017b, c; outline, treated as in Venturiaceae), cultures and sequences are unavailable thus we treat as Ascomycota incertae sedis.

Gaeumannomycella Hern.-Restr. \& Crous 2016, Magnaporthaceae, Magnaporthales, Sordariomycetes, one species, type: G. caricis Hern.-Restr. \& Crous, hyphomycetous, saprobes, UK, see Hernández-Restrepo et al. et al. (2016; taxonomy, phylogeny), Wijayawardene et al. (2017c; outline), cultures and sequences are available. 
Gallaicolichen Sérus. \& Lücking 2007, Ascomycota, genera incertae sedis, one species, type: G. pacificus Sérus. \& Lücking, asexual morph unknown, foliicolous lichen, terrestrial, Hawaiian Island, see Lumbsch \& Huhndorf (2010; outline), Wijayawardene et al. (2017c; outline), sequences are unavailable.

Geneosperma Rifai 1968, Pyronemataceae, Pezizales, Pezizomycetes, two species, type: G. geneosporum Rifai, saprobes, cosmopolitan, see Lumbsch \& Huhndorf (2010; outline), Jaklitsch et al. (2016; classification), Wijayawardene et al. (2017c; outline), sequences are unavailable.

Glischroderma Fuckel 1870, Pezizaceae, Pezizales, Pezizomycetes, c. ten species, type: C. cinctum Fuckel, coelomycetous, saprobes, Europe, see Wijayawardene et al. (2012, 2017b, c; outline), Kirk et al. (2013; not listed), cultures and sequences are available.

Gloeocoryneum Weindlm. 1964, Ascomycota genera incertae sedis, three species, type: G. cinereum (Dearn.) Weindlm., coelomycetous, saprobes, terrestrial, cosmopolitan, see Kirk et al. (2008; treated as a synonym of Leptomelanconium), Wijayawardene et al. (2012, 2016, 2017b, c; outline, taxonomy), Kirk et al. (2013; not listed), cultures and sequences are unavailable.

Gloeodes Colby 1920, Ascomycota genera incertae sedis, one species, type: G. pomigena (Schwein.) Colby, coelomycetous, saprobes, pathogens, terrestrial, cosmopolitan, see Wijayawardene et al. (2012, 2017b, c; outline), Kirk et al. (2013; genus accepted), cultures and sequences are unavailable.

Goidanichiella G.L. Barron ex W. Gams 2009, Ascomycota genera incertae sedis, one species, type: G. barronii W. Gams, Steiman \& Seigle-Mur., coelomycetous, saprobes, terrestrial, cosmopolitan, see Gams et al. (2009; new species), Wijayawardene et al. (2012, 2017b, c; outline), Kirk et al. (2013; genus accepted), cultures and sequences are available.

Graminopassalora U. Braun, C. Nakash., Videira \& Crous 2017, Mycosphaerellaceae, Capnodiales, Dothideomycetes, one species, type: G. graminis (Fuckel) U. Braun, C. Nakash., Videira \& Crous, hyphomycetous, pathogens, terrestrial, cosmopolitan, see Videira et al. (2017; taxonomy, phylogeny), Wijayawardene et al. (2017c; outline), cultures and sequences are available.

Hawksworthiomyces Z.W. de Beer, Marinc. \& M.J. Wingf. 2016, Ophiostomataceae, Magnaporthales, Sordariomycetes, five species, type: H. lignivorus (De Mey., Z.W. de Beer \& M.J. Wingf.) Z.W. de Beer, Marinc. \& M.J. Wingf., hyphomycetous, saprobes, South Africa, see de Beer et al. (2016a, b; taxonomy, phylogeny), Wijayawardene et al. (2017c; outline), cultures and sequences are available.

Helicominopsis Deighton 1960, Ascomycota genera incertae sedis, one species, type: H. fici Deighton, hyphomycetous, saprobes, terrestrial, Africa, see Seifert et al. (2011; morphology, treated as a distinct genus), Wijayawardene et al. (2012, 2017b, c; outline), Kirk et al. (2013; genus accepted), cultures and sequences are unavailable.

Himantia Pers. 1801, Ascomycota genera incertae sedis, one species, type: H. candida (Huds.) Pers., sterile, saprobes, terrestrial, Europe, see Kirk et al. (2008; genus accepted), Wijayawardene et al. (2012, 2017b, c; outline), Kirk et al. (2013; not listed), cultures and sequences are unavailable.

Hyalocercosporidium Videira \& Crous 2017, Mycosphaerellaceae, Capnodiales, Dothideomycetes, one species, type: H. desmodii Videira \& Crous, hyphomycetous, pathogens, terrestrial, Brazil, see Videira et al. (2017; taxonomy, phylogeny), Wijayawardene et al. (2017c; outline), cultures and sequences are available. 
Hyalopyrenia $\mathrm{H}$. Harada 1996, Ascomycota genera incertae sedis, six species, type: $H$. japonica $\mathrm{H}$. Harada, asexual morph unknown, saprobes, terrestrial, Asia, see Lumbsch \& Huhndorf (2009; outline), Kirk et al. (2013; genus accepted), Wijayawardene et al. (2017c; outline), cultures and sequences are unavailable.

Hyalozasmidium U. Braun, C. Nakash., Videira \& Crous 2017, Mycosphaerellaceae, Capnodiales, Dothideomycetes, two species, type: H. aerohyalinosporum (Crous \& Summerell) Videira \& Crous, hyphomycetous, pathogens or saprobes, terrestrial, South Africa, Australia, see Videira et al. (2017; taxonomy, phylogeny), Wijayawardene et al. (2017c; outline), cultures and sequences are available.

Hymenobactron (Sacc.) Höhn. 1916, Ascomycota genera incertae sedis, one species, type: $H$. candida (Huds.) Pers., hyphomycetous, saprobes, terrestrial, Europe, see Wijayawardene et al. (2012, 2017b, c; outline), Kirk et al. (2013; genus accepted), cultures and sequences are unavailable.

Hyphozyma de Hoog \& M.T. Sm. 1981, Ascomycota genera incertae sedis, six species, type: $H$. variabilis de Hoog \& M.T. Sm., hyphomycetous, saprobes, terrestrial, aquatic, cosmopolitan, see Seifert et al. (2011; morphology), Wijayawardene et al. (2012, 2017b, c; outline), Kirk et al. (2013; genus accepted), cultures and sequences are available.

Impudentia Vujan. 2003, Ascomycota genera incertae sedis, two species, type: I. crioceris Vujan., hyphomycetous, on insects, terrestrial, aquatic, cosmopolitan, see Seifert et al. (2011; not listed), Wijayawardene et al. (2012, 2017b, c; outline), cultures and sequences are unavailable.

Juxtiphoma Valenzuela-Lopez, Cano, Crous, Guarro \& Stchigel 2017, Didymellaceae, Pleosporales, Dothideomycetes, one species, type: J. eupyrena (Sacc.) Valenzuela-Lopez, Cano, Crous, Guarro \& Stchigel, coelomycetous, saprobes or pathogens, Germany, The Netherlands, see Valenzuela-Lopez et al. (2017; morphology, phylogeny), Wijayawardene et al. (2017c; outline), cultures and sequences are available.

Kalbionora Sodamuk, S.D. Leav. \& Lumbsch 2017, Malmideaceae, Lecanorales, Lecanoromycetes, one species, type: K. palaeotropica Sodamuk, Leavitt \& Lumbsch, lichenized, terrestrial, Southeast Asia and Australia, see Sodamuk et al. (2017; taxonomy), Wijayawardene et al. (2017c; outline), cultures and sequences are available.

Kamatia V.G. Rao \& Subhedar 1976, Ascomycota genera incertae sedis, one species, type: K. indica V.G. Rao \& Subhedar, hyphomycetous, saprobes, terrestrial, Asia, see Kirk et al. (2008; treated as a synonym of Pseudodictyosporium Matsush.), Seifert et al. (2011; treated as a distinct genus), Wijayawardene et al. (2012, 2017b, c; outline), cultures and sequences are unavailable.

Kendrickiella K. Jacobs \& M.J. Wingf. 2001, Ascomycota genera incertae sedis, one species, type: K. phycomyces (Auersw.) K. Jacobs \& M.J. Wingf., hyphomycetous, saprobes, on fungi, terrestrial, cosmopolitan, see Seifert et al. (2011; morphology), Kiyuna et al. (2012; DNA), Wijayawardene et al. (2012, 2017b, c; outline), cultures and sequences are unavailable.

Kutilakesa Subram. 1956, Ascomycota genera incertae sedis, two species, type: K. madreeya Subram., hyphomycetous, saprobes, terrestrial, cosmopolitan, see Kirk et al. (2008; treated as a synonym of Sarcopodium Ehrenb.), Seifert et al. (2011; morphology), Wijayawardene et al. (2012, 2017 b, c; outline), cultures and sequences are unavailable.

Lagenomyces Cavalc. \& A.A. Silva 1972, Ascomycota genera incertae sedis, two species, type: K. marginalis Cavalc. \& A.A. Silva, coelomycetous, saprobes, terrestrial, cosmopolitan, see 
Wijayawardene et al. (2012, 2017b, c; outline), Kirk et al. (2013; not listed), cultures and sequences are unavailable.

Lepra Scop. 1777, Pertusariales genera incertae sedis, Lecanoromycetes, 72 species, type: Lichen albescens Huds., lichenized, see Wei et al. (2017; resurrected genus), Wijayawardene et al. (2017c; outline), sequences are available.

Lichenodiplisiella S.Y. Kondr. \& Kudratov 2002, Ascomycota genera incertae sedis, one species, type: L. makarevichiae S.Y. Kondr. \& Kudratov, coelomycetous, saprobes, terrestrial, Tadzhikistan, see Wijayawardene et al. (2012, 2017b, c; outline), Kirk et al. (2013; not listed), cultures and sequences are unavailable.

Luxuriomyces R.F. Castañeda 1988, Ascomycota genera incertae sedis, one species, type: L. grandis R.F. Castañeda, hyphomycetous, saprobes, terrestrial, Caribbean, see Seifert et al. (2011; morphology), Wijayawardene et al. (2012, 2017b, c; outline), Kirk et al. (2013; not listed), cultures and sequences are unavailable.

Macrotrichum Grev. 1825, Ascomycota genera incertae sedis, two species, type: data inadequate, hyphomycetous, saprobes, terrestrial, see Seifert et al. (2011; morphology), Wijayawardene et al. (2012, 2017b, c; outline), Kirk et al. (2013; not listed), cultures and sequences are unavailable.

Madagascaromyces U. Braun, C. Nakash., Videira \& Crous 2017, Mycosphaerellaceae, Capnodiales, Dothideomycetes, one species, type: M. intermedius (Crous \& M.J. Wingf.) Videira \& Crous, hyphomycetous, pathogens or saprobes, terrestrial, Madagascar, see Videira et al. (2017; taxonomy, phylogeny), Wijayawardene et al. (2017c; outline), cultures and sequences are available.

Malvinia Döbbeler 2003, Ostropales, genera incertae sedis, Lecanoromycetes, one species, type: M. endoderma Döbbeler, saprobes?, Falkland Island, see Lumbsch \& Huhndorf (2010; outline), Wijayawardene et al. (2017c; outline), sequences are available.

Manginella Bat. \& H. Maia 1961, Ascomycota genera incertae sedis, three species, type: M. annonae Bat. \& H. Maia, coelomycetous, saprobes, terrestrial, Brazil, see Wijayawardene et al. (2012, 2017b, c; outline), Kirk et al. (2013; not listed), cultures and sequences are unavailable.

Margarinomyces Laxa 1930, Ascomycota genera incertae sedis, one species, type: M. bubakii Laxa, hyphomycetous, saprobes, on human, terrestrial, Brazil, see Seifert et al. (2011; genus accepted, morphology), Wijayawardene et al. (2012, 2017b, c; outline), Kirk et al. (2013; not listed), cultures and sequences are unavailable.

Maronina Hafellner \& R.W. Rogers 1990, Parmeliaceae, Lecanorales, Lecanoromycetes, 10 species, type: M. australiensis Hafellner \& R.W. Rogers, lichenized, see Hafellner \& Rogers (1990; taxonomy), Papong et al. (2011; taxonomy, phylogeny), Divakar et al. (2017; taxonomy, phylogeny), sequences are available.

Medicopsis Gruyter, Verkley \& Crous 2012, Trematosphaeriaceae, Pleosporales, Dothideomycetes, one species, type: M. romeroi (Borelli) Gruyter, Verkley \& Crous, coelomycetous, sexual morph unknown, pathogens, terrestrial, cosmopolitan, see de Gruyter et al. (2012; taxonomy, phylogeny), Wijayawardene et al. (2014, 2017b, c; outline), ex-type of the type: CBS 252.60.

Micronematomyces U. Braun, C. Nakash., Videira \& Crous 2017, Mycosphaerellaceae, Capnodiales, Dothideomycetes, one species, type: M. caribensis (Crous \& Den Breeÿen) U. Braun, 
C. Nakash., Videira \& Crous, hyphomycetous, pathogens or saprobes, terrestrial, Cuba, Jamaica, see Videira et al. (2017; taxonomy, phylogeny), Wijayawardene et al. (2017c; outline), cultures and sequences are available.

Monochaetopsis Pat. 1931, Ascomycota genera incertae sedis, one species, type: M. antirrhini Pat., coelomycetous, saprobes, terrestrial, North Africa, see Wijayawardene et al. (2012, 2017b, c; outline), Kirk et al. (2013; genus accepted), cultures and sequences are unavailable.

Mucosetospora M. Morelet 1972, Ascomycota genera incertae sedis, one species, type: M. gallica (M. Morelet) M. Morelet, coelomycetous, saprobes, terrestrial, France, see Wijayawardene et al. (2012, 2017b, c; outline), Kirk et al. (2013; genus accepted), cultures and sequences are unavailable.

Mycocentrodochium K. Matsush. \& Matsush. 1996, Ascomycota genera incertae sedis, one species, type: M. gallica (M. Morelet) M. Morelet, hyphomycetous, saprobes, terrestrial, Asia, see Seifert et al. (2011; morphology), Wijayawardene et al. (2012, 2017b, c; outline), Kirk et al. (2013; genus accepted), cultures and sequences are unavailable.

Mycosisymbrium Carris 1994, Sympoventuriaceae, Venturiales, Dothideomycetes, one species, type: $M$. cirrhosum Carris, hyphomycetous, sexual morph unknown, saprobes, terrestrial, North America, see Kirk et al. (2008; treated as a synonym of Scolecobasidiella M.B. Ellis.), Seifert et al. (2011; treated as a distinct genus), Wijayawardene et al. (2017c; outline), cultures and sequences are available.

Necraphidium Cif. 1951, Ascomycota genera incertae sedis, one species, type: N. zoophilum (Sacc. \& Trotter) Cif., hyphomycetous, on larvae of Callipterus, terrestrial, Italy, see Wijayawardene et al. (2012, 2017b, c; outline), Kirk et al. (2013; genus accepted), cultures and sequences are unavailable.

Neocercosporidium Videira \& Crous 2017, Mycosphaerellaceae, Capnodiales, Dothideomycetes, one species, type: N. smilacis (Thüm.) U. Braun, C. Nakash., Videira \& Crous, hyphomycetous, pathogens or saprobes, terrestrial, Cuba, Jamaica, see Videira et al. (2017; taxonomy, phylogeny), Wijayawardene et al. (2017c; outline), cultures and sequences are available.

Neomarssoniella U. Braun 1991, Ascomycota genera incertae sedis, one species, type: $N$. juglandis (Lib.) U. Braun, coelomycetous, saprobes, terrestrial, Europe, N. America, see Wijayawardene et al. (2012, 2017b, c; outline), Kirk et al. (2013; genus accepted), cultures and sequences are unavailable.

Neophloeospora U. Braun, C. Nakash., Videira \& Crous 2017, Mycosphaerellaceae, Capnodiales, Dothideomycetes, one species, type: N. maculans (Bérenger) Videira \& Crous, asexual morph hyphomycetous, pathogens, terrestrial, New Zealand, see Videira et al. (2017; taxonomy, phylogeny), Wijayawardene et al. (2017c; outline), cultures and sequences are available.

Neopyrenochaeta Valenzuela-Lopez, Crous, Stchigel, Guarro \& Cano2017, Neopyrenochaetaceae, Pleosporales, Dothideomycetes, four species, type: N. acicola (Moug. \& Lév) Valenzuela-Lopez, Crous, Stchigel, Guarro \& Cano, coelomycetous, saprobes, The Netherlands, South Africa, India, see Valenzuela-Lopez et al. (2017; morphology, phylogeny), Wijayawardene et al. (2017c; outline), cultures and sequences are available.

Neopyrenochaetopsis Valenzuela-Lopez, Cano, Guarro \& Stchigel 2017, Pyrenochaetopsidaceae, Pleosporales, Dothideomycetes, one species, type: N. hominis Valenzuela-Lopez, Cano, Guarro \& 
Stchigel, coelomycetous, from human skin tissue, USA, see Valenzuela-Lopez et al. (2017; morphology, phylogeny), Wijayawardene et al. (2017c; outline), cultures and sequences are available.

Nephromopsis Müll. Arg. 1891 (=Ahtiana Goward 1986; = Arctocetraria Kärnefelt \& Thell 1993; = Cetrariopsis Kurok. 1980; = Cetreliopsis M.J. Lai. 1980; = Flavocetraria Ka“rnefelt \& A. Thell 1994; = Flavocetrariella D.D. Awasthi 2007; = Kaernefeltia Thell \& Goward 1996; = Masonhalea Ka"rnefelt 1977; = Tuckermanella Essl. 2003; = Tuckermanopsis Gyeln. 1933 fide Divakar et al. 2017, Lücking et al. 2017), Parmeliaceae, Lecanorales, Lecanoromycetes, 62 species, type: N. stracheyi (C. Bab.) Müll. Arg., asexual morph unknown, lichenized, terrestrial, Argentina, see Thell et al. (2009; DNA, phylogeny), Lumbsch \& Huhndorf (2010; outline), Kirk et al. (2013; genus accepted), Randlane et al. (2013; new species), Lücking et al. (2017; classification), Divakar et al. (2017; phylogeny), sequences are available.

Nothopassalora U. Braun, C. Nakash., Videira \& Crous 2017, Mycosphaerellaceae, Capnodiales, Dothideomycetes, one species, type: N. maculans (Bérenger) Videira \& Crous, asexual morph hyphomycetous, pathogens, terrestrial, Australia, USA, see Videira et al. (2017; taxonomy, phylogeny), Wijayawardene et al. (2017c; outline), cultures and sequences are available.

Nothopericoniella Videira \& Crous 2017, Mycosphaerellaceae, Capnodiales, Dothideomycetes, one species, type: N. perseae-macranthae (Hosag. \& U. Braun) Videira \& Crous, hyphomycetous, pathogens, terrestrial, India, Taiwan, see Videira et al. (2017; taxonomy, phylogeny), Wijayawardene et al. (2017c; outline), cultures and sequences are available.

Nothophaeocryptopus Videira, C. Nakash. \& Crous 2017, Mycosphaerellaceae, Capnodiales, Dothideomycetes, one species, type: N. gaeumannii (T. Rohde) Videira, C. Nakash., U. Braun \& Crous, hyphomycetous, pathogens, terrestrial, Austria, Germany, see Videira et al. (2017; taxonomy, phylogeny), Wijayawardene et al. (2017c; outline), cultures and sequences are available.

Odontura Clem. 1909, Odontotremataceae, Ostropales, Lecanoromycetes, c. 20 species, type: $O$. rhaphidospora (Rehm) Clem., asexual morph unknown, saprobes?, terrestrial, Europe, see Lumbsch \& Huhndorf (2010; outline), Wijayawardene et al. (2017c; outline), sequences are available.

Ovatospora X. Wei Wang, Samson \& Crous 2016, Chaetomiaceae, Sordariales, Sordariomycetes, two species, type: O. brasiliensis (Batista \& Pontual) X. Wei Wang \& Samson, asexual morph unknown, indoor fungus, cosmopolitan, see Wang et al. (2016; taxonomy, phylogeny), Wijayawardene et al. (2017c; outline), sequences are available.

Pachyramichloridium Videira \& Crous 2017, Mycosphaerellaceae, Capnodiales, Dothideomycetes, one species, type: P. pini (de Hoog \& Rahman) C. Nakash., Videira \& Crous, hyphomycetous, pathogens or saprobes, terrestrial, UK, see Videira et al. (2017; taxonomy, phylogeny), Wijayawardene et al. (2017c; outline), cultures and sequences are available.

Palawaniopsis Bat., Cif. \& Nascim. 1959, Ascomycota genera incertae sedis, one species, type: $N$. dovyalidis Bat., Cif. \& Nascim., coelomycetous, saprobes, terrestrial, Europe, N. America, see Wijayawardene et al. (2012, 2017b, c; outline), Kirk et al. (2013; genus accepted), cultures and sequences are unavailable.

Paracercosporidium Videira \& Crous 2017, Mycosphaerellaceae, Capnodiales, Dothideomycetes, two species, type: P. microsorum (Sacc.) U. Braun, C. Nakash., Videira \& Crous, hyphomycetous, 
pathogens, terrestrial, cosmopolitan, see Videira et al. (2017; taxonomy, phylogeny), Wijayawardene et al. (2017c; outline), cultures and sequences are available.

Paracucurbitaria Valenzuela-Lopez, Stchigel, Guarro \& Cano 2017, Cucurbitariaceae, Pleosporales, Dothideomycetes, two species, type: P. corni (Bat. \& A.F. Vital) Valenzuela-Lopez, Stchigel, Guarro \& Cano., coelomycetous, saprobes or pathogens, The Netherlands, Italy, see Valenzuela-Lopez et al. (2017; morphology, phylogeny), Wijayawardene et al. (2017c; outline), cultures and sequences are available.

Paraepicoccum Matsush. 1993, Pleosporales, genera incertae sedis, Dothideomycetes, one species, type: P. amazonense Matsush., hyphomycetous, sexual morph unknown, saprobes, terrestrial, South America, see Seifert et al. (2011; morphology), Thambugala et al. (2017; phylogeny), Wijayawardene et al. (2017c; outline), cultures and sequences are available.

Parafabraea Chen, Verkley \& Crous 2016, Dermateaceae, Helotiales, Leotiomycetes, two species, type: P. eucalypti (Cheew. \& Crous) Chen, Verkley \& Crous, asexual morph coelomycetous, cosmopolitan, see Chen et al. (2016; taxonomy, phylogeny), Wijayawardene et al. (2017c; outline), cultures and sequences are available.

Paramassariosphaeria Wanas., E.B.G. Jones \& K.D. Hyde 2016, Didymosphaeriaceae, Pleosporales, Dothideomycetes, one species, type: P. clematidicola Wanas., Camporesi, E.B.G. Jones \& K.D. Hyde, asexual morph unknown, saprobes, terrestrial, Italy, see Wanasinghe et al. (2016; taxonomy, phylogeny), Wijayawardene et al. (2017c; outline), cultures and sequences are available.

Paramycovellosiella Videira, H.D. Shin \& Crous 2017, Mycosphaerellaceae, Capnodiales, Dothideomycetes, one species, type: P. passaloroides (G. Winter) Videira, H.D. Shin \& Crous, hyphomycetous, pathogens, terrestrial, Republic of Korea, see Videira et al. (2017; taxonomy, phylogeny), Wijayawardene et al. (2017c; outline), cultures and sequences are available.

Parapallidocercospora Videira, Crous, U. Braun, C. Nakash. 2017, Mycosphaerellaceae, Capnodiales, Dothideomycetes, two species, type: P. colombiensis (Crous \& M.J. Wingf.) Videira $\&$ Crous, asexual morph hyphomycetous, pathogens, terrestrial, Colombia, Thailand, see Videira et al. (2017; taxonomy, phylogeny), Wijayawardene et al. (2017c; outline), cultures and sequences are available.

Parapyrenochaeta Valenzuela-Lopez, Crous, Stchigel, Guarro \& Cano 2017, Pyrenochaetopsidaceae, Pleosporales, Dothideomycetes, three species, type: P. protearum (Crous) Valenzuela-Lopez, Crous, Stchigel, Guarro \& Cano, coelomycetous, saprobes, France, South Africa, Australia, see Valenzuela-Lopez et al. (2017; morphology, phylogeny), Wijayawardene et al. (2017; outline), cultures and sequences are available.

Pazschkeella Syd. \& P. Syd. 1901, Ascomycota genera incertae sedis, two species, type: P. brasiliensis Syd. \& P. Syd., coelomycetous, sexual morph unknown, saprobes, terrestrial, Brazil, Philippines, see Kirk et al. (2013; genus accepted), Wijayawardene et al. (2017c; outline), cultures and sequences are unavailable thus we treat as Ascomycota incertae sedis.

Phaeomycocentrospora Crous, H.D. Shin \& U. Braun 2012, Didymellaceae, Pleosporales, Dothideomycetes, one species, type: P. cantuariensis (E.S. Salmon \& Wormald) Crous, H.D. Shin \& U. Braun, hyphomycetous, sexual morph unknown, pathogens, terrestrial, cosmopolitan, see Crous et al. (2012; taxonomy, phylogeny), Trakunyingcharoen et al. (2014; phylogeny), Wijayawardene et al. (2014, 2017c; outline), cultures and sequences are available. 
Phaeophomopsis Höhn. 1917, Ascomycota genera incertae sedis, one species, type: P. hederae (Desm.) Höhn., coelomycetous, saprobes, terrestrial, France, see Wijayawardene et al. (2012, 2017b, c; outline), Kirk et al. (2013; genus accepted), cultures and sequences are unavailable.

Phruensis Pinruan 2004, Tirisporellaceae, Tirisporellales, Sordariomycetes, one species, type: $P$. brunneispora Pinruan, asexual morph hyphomycetous, aquatic, saprobes, Thailand, see Lumbsch \& Huhndorf (2010; outline), Wijayawardene et al. (2017c; outline), sequences are available.

Plectopycnis Bat. \& A.F. Vital 1959, Ascomycota genera incertae sedis, one species, type: $P$. coccolobae Bat. \& A.F. Vital, coelomycetous, sexual morph unknown, saprobes, terrestrial, neotropics, see Kirk et al. (2013; not listed), Wijayawardene et al. (2017; outline, treated as in Dothideomycetes), cultures and sequences are unavailable thus we treat as Ascomycota incertae sedis.

Pleopassalora Videira \& Crous 2017, Mycosphaerellaceae, Capnodiales, Dothideomycetes, one species, type: D. daleae (Ellis \& Kellerm.) Videira \& Crous, hyphomycetous, pathogens, terrestrial, Mexico, USA, see Videira et al. (2017; taxonomy, phylogeny), Wijayawardene et al. (2017c; outline), cultures and sequences are available.

Pleuropassalora U. Braun, C. Nakash., Videira \& Crous 2017, Mycosphaerellaceae, Capnodiales, Dothideomycetes, one species, type: P. armatae (Crous \& A.R. Wood) U. Braun, C. Nakash., Videira \& Crous, hyphomycetous, pathogens, terrestrial, Switzerland, see Videira et al. (2017; taxonomy, phylogeny), Wijayawardene et al. (2017c; outline), cultures and sequences are available.

Pluripassalora Videira \& Crous 2017, Mycosphaerellaceae, Capnodiales, Dothideomycetes, two species, type: P. bougainvilleae (Munt.-Cvetk.) U. Braun, C. Nakash., Videira \& Crous, hyphomycetous, pathogens, terrestrial, Australia, see Videira et al. (2017; taxonomy, phylogeny), Wijayawardene et al. (2017c; outline), cultures and sequences are available.

Potamomyces K.D. Hyde 1995, Ascomycota genera incertae sedis, ten species, type: $P$. armatisporus K.D. Hyde, asexual morph unknown, saprobes, terrestrial, cosmopolitan, see Lumbsch \& Huhndorf (2009; outline), Kirk et al. (2013; genus accepted), cultures and sequences are unavailable.

Praetumpfia Jaklitsch \& Voglmayr 2017, Melanommataceae, Pleosporales, Dothideomycetes, one species, type: P. obducens (Schumach.) Jaklitsch \& Voglmayr, asexual morph coelomycetous, saprobes, terrestrial, Europe, see Jaklitsch \& Voglmayr (2017; taxonomy, phylogeny), Wijayawardene et al. (2017c; outline), cultures and sequences are available.

Prathoda Subram. 1956, Ascomycota genera incertae sedis, two species, type: P. saparva Subram., hyphomycetous, sexual morph unknown, saprobes, terrestrial, Africa, Asia, see Kirk et al. (2013; not listed), Wijayawardene et al. (2017c; outline), cultures and sequences are unavailable thus we treat as Ascomycota incertae sedis.

Propoliopsis Rehm 1914, Stictidaceae, Ostropales, Lecanoromycetes, one species, type: P. arengae Rehm, asexual morph unknown, saprobes?, terrestrial, Asia, North America, see Lumbsch \& Huhndorf (2010; outline), Wijayawardene et al. (2017c; outline), sequences are available.

Pseudotricharina Van Vooren, S. Tello \& M. Vega 2015, Pyronemataceae, Pezizales, Pezizomycetes, two species, type: P. intermedia Van Vooren, S. Tello \& M. Vega, asexual morph unknown, saprobes, terrestrial, Europe, see Van Vooren et al. (2015, 2017; taxonomy, new species), Wijayawardene et al. (2017c; outline), sequences are available. 
Pseudeurotium J.F.H. Beyma 1937 (= Teberdinia Sogonov, W. Gams, Summerb. \& Schroers 2005 fide Rossman et al. 2016), Pseudeurotiaceae, Ascomycota families incertae sedis, seven species, type: P. zonatum J.F.H. Beyma, asexual morph is formerly known in Teberdinia, cosmopolitan, see Seifert et al. (2011; asexual morph), Rossman et al. (2016; nomenclature), Wijayawardene et al. (2017c; outline), cultures and sequences are available.

Pseudochaetosphaeronema Punith. 1979, Pleosporales, genera incertae sedis, Dothideomycetes, two species, type: P. larense (Borelli \& R. Zamora) Punith., coelomycetous, sexual morph unknown, saprobes, terrestrial, cosmopolitan, see Kirk et al. (2013; genus acceptd), Zhang et al. (2016; new species), Wijayawardene et al. (2017c; outline), cultures and sequences are available

Pseudofabraea Chen, Verkley \& Crous 2016, Dermateaceae, Helotiales, Leotiomycetes, one species, type: P. citricarpa (L. Zhu, K.D. Hyde \& H.Y. Li) Chen, Verkley \& Crous, coelomycetous, cosmopolitan, see Chen et al. (2016; taxonomy, phylogeny), Wijayawardene et al. (2017c; outline), cultures and sequences are available.

Pseudopericoniella Videira \& Crous 2017, Mycosphaerellaceae, Capnodiales, Dothideomycetes, one species, type: P. levispora (Arzanlou et al.) Videira \& Crous, hyphomycetous, pathogens, terrestrial, Sri Lanka, see Videira et al. (2017; taxonomy, phylogeny), Wijayawardene et al. (2017c; outline), cultures and sequences are available.

Pseudophaeophleospora C. Nakash., Videira \& Crous 2017, Mycosphaerellaceae, Capnodiales, Dothideomycetes, two species, type: P. stonei (Crous) C. Nakash., Videira \& Crous, hyphomycetous, pathogens, terrestrial, Australia, New Zealand, see Videira et al. (2017; taxonomy, phylogeny), Wijayawardene et al. (2017c; outline), cultures and sequences are available.

Pseudophialophora J. Luo \& N. Zhang 2014, Magnaporthaceae, Magnaporthales, Sordariomycetes, eight species, type: P. eragrostis J. Luo \& N. Zhang, hyphomycetous, saprobes, cosmopolitan, see Luo et al. (2014b, 2015a, b; taxonomy, phylogeny, new species), Wijayawardene et al. (2017c; outline), cultures and sequences are available.

Pseudopyrenochaeta Valenzuela-Lopez, Crous, Stchigel, Guarro \& Cano 2017, Pseudopyrenochaetaceae, Pleosporales, Dothideomycetes, two species, type: P. lycopersici (R.W. Schneid. \& Gerlach) Valenzuela-Lopez, Crous, Stchigel, Guarro \& Cano, coelomycetous, from soil, saprobes, Germany, The Netherlands, see Valenzuela-Lopez et al. (2017; morphology, phylogeny), Wijayawardene et al. (2017c; outline), cultures and sequences are available.

Pseudozasmidium Videira \& Crous 2017, Mycosphaerellaceae, Capnodiales, Dothideomycetes, four species, type: P. parkii (Crous \& Alfenas) Videira \& Crous, asexual morph hyphomycetous, pathogens, terrestrial, Australia, Brazil, Vietnam, see Videira et al. (2017; taxonomy, phylogeny), Wijayawardene et al. (2017c; outline), cultures and sequences are available.

Pullospora Faurel \& Schotter 1965, Ascomycota genera incertae sedis, one species, type: $P$. tetrachaeta Faurel \& Schotter, coelomycetous, coprophilous, terrestrial, France, see Wijayawardene et al. (2012, 2017b, c; outline), Kirk et al. (2013; genus accepted), cultures and sequences are unavailable.

Ragnhildiana Solheim 1931, Mycosphaerellaceae, Capnodiales, Dothideomycetes, six species, type: P. agerati (F. Stevens) F. Stevens \& Solheim, hyphomycetous, pathogens, terrestrial, cosmopolitan, see Videira et al. (2017; taxonomy, phylogeny), Wijayawardene et al. (2017c; outline), cultures and sequences are available. 
Ravenelula Speg. 1881, Lecanoromycetes genera incertae sedis, one species, type: $R$. gainesvillensis Speg., saprobes?, America, see Lumbsch \& Huhndorf (2010; outline), Wijayawardene et al. (2017c; outline), sequences are unavailable.

Remotididymella Valenzuela-Lopez, Crous, Cano, Guarro \& Stchigel 2017, Didymellaceae, Pleosporales, Dothideomycetes, two species, type: $R$. destructiva (Plowr.) Valenzuela-Lopez, Cano, Crous, Guarro \& Stchigel., coelomycetous, saprobes or pathogens, Guadeloupe, USA, The Netherlands, Tonga, see Valenzuela-Lopez et al. (2017; morphology, phylogeny), Wijayawardene et al. (2017; outline), cultures and sequences are available.

Rhachisphaerella U. Braun, C. Nakash., Videira \& Crous 2017, Mycosphaerellaceae, Capnodiales, Dothideomycetes, one species, type: R. mozambica (Arzanlou \& Crous) Videira \& Crous, asexual morph hyphomycetous, pathogens, terrestrial, Mozambique, see Videira et al. (2017; taxonomy, phylogeny), Wijayawardene et al. (2017c; outline), cultures and sequences are available.

Rhynchomyces Willk. 1866, Ascomycota genera incertae sedis, one species, type: $R$. violaceus Willk., hyphomycetous, saprobes, terrestrial, see Seifert et al. (2011; notes), Wijayawardene et al. (2012, 2017b, c; outline), Kirk et al. (2013; genus accepted), cultures and sequences are unavailable.

Rickiella Syd. \& P. Syd. ex Rick 1904, Sarcoscyphaceae, Pezizales, Pezizomycetes, two species, $R$. transiens Syd. \& P. Syd. ex Rick, saprobes, cosmopolitan, see Kirk et al. (2008; treated as a synonym of Phillipsia Berk.), Lumbsch \& Huhndorf (2010; outline), Jaklitsch et al. (2016; classification), Wijayawardene et al. (2017c; outline), sequences are available.

Riclaretia Peyronel 1915, Ascomycota genera incertae sedis, one species, type: $R$. urticae Peyronel, hyphomycetous, saprobes, terrestrial, see Seifert et al. (2011; notes, doubtful), Wijayawardene et al. (2012, 2017b, c; outline), Kirk et al. (2013; genus accepted), cultures and sequences are unavailable.

Rupestriomyces Lei Su, Li Y. Guo \& Xing Z. Liu 2015, Dothideomycetes, genera incertae sedis, five species, type: $R$. ampulliformis Lei Su, Li Y. Guo \& Xing Z. Liu, hyphomycetous, sexual morph unknown, rock-inhabiting, terrestrial, China, see Su et al. (2015; taxonomy), taxonomy, Wijayawardene et al. (2017c; outline), cultures and sequences are available.

Sanjuanomyces R.F. Castañeda \& W.B. Kendr. 1991, Ascomycota genera incertae sedis, one species, type: S. elegans R.F. Castañeda \& W.B. Kendr., hyphomycetous, on leaves, terrestrial, Caribbean, see Seifert et al. (2011; morphology), Wijayawardene et al. (2012, 2017b, c; outline), Kirk et al. (2013; genus accepted), cultures and sequences are unavailable.

Sarophorum Syd. \& P. Syd. 1917, Ascomycota genera incertae sedis, one species, type: S. ledermannii Syd. \& P. Syd., hyphomycetous, on seeds, in soil, terrestrial, Pantropical, see Seifert et al. (2011; morphology), Wijayawardene et al. (2012, 2017b, c; outline), Kirk et al. (2013; not listed), cultures and sequences are unavailable.

Scleroramularia Batzer \& Crous 2011, Pleosporales, genera incertae sedis, Dothideomycetes, two species, type: S. pomigena Batzer \& Crous, hyphomycetous, sexual morph unknown, saprobes, terrestrial, cosmopolitan, see Li et al. (2011; taxonomy), Gao et al. (2015; new species), Wijayawardene et al. (2017c; outline), cultures and sequences are available. 
Semipseudocercospora J.M. Yen 1983, Ascomycota genera incertae sedis, two species, type: $S$. peristrophes-acuminatae (J.M. Yen) J.M. Yen, hyphomycetous, on leaves, terrestrial, Asia, see Seifert et al. (2011; morphology), Wijayawardene et al. (2012, 2017b, c; outline), Kirk et al. (2013; not listed), cultures and sequences are unavailable.

Siamia V. Robert, Decock \& R.F. Castañeda 2000, Ascomycota genera incertae sedis, one species, type: S. luxuriosa V. Robert, Decock \& R.F. Castañeda, hyphomycetous, saprobes, terrestrial, Asia, see Seifert et al. (2011; morphology), Wijayawardene et al. (2012, 2017b, c; outline), cultures and sequences are unavailable.

Similiphoma Valenzuela-Lopez, Crous, Cano, Guarro \& Stchigel 2017, Didymellaceae, Pleosporales, Dothideomycetes, two species, type: S. crystallifera (de Gruyter et al.) ValenzuelaLopez, Crous, Cano, Guarro \& Stchigel, coelomycetous, saprobes or pathogens, Austria, see Valenzuela-Lopez et al. (2017; morphology, phylogeny), Wijayawardene et al. (2017c; outline), cultures and sequences are available.

Simmonsiella J.L. Crane \& A.N. Mill. 2016, Ascomycota genera incertae sedis, one species, type: S. ndjilensis (É. Kiffer) J.L. Crane \& A.N. Mill., hyphomycetous, saprobes, terrestrial, Zaire, see Crane \& Miller (2016; taxonomy), Wijayawardene et al. (2017c; outline), cultures and sequences are unavailable.

Sirodesmium De Not. 1849, Pleosporales, genera incertae sedis, Dothideomycetes, two species, type: S. granulosum Sacc., coelomycetous, sexual morph unknown, saprobes, terrestrial, cosmopolitan, see Kirk et al. (2008; treated as a synonym of Coniosporium Link), Ruibal et al. (2009; phylogeny), Wijayawardene et al. (2017c; outline), cultures and sequences are available.

Sphaeridium Fresen. 1852, Ascomycota genera incertae sedis, c. 18 species, type: S. vitellinum Fresen., hyphomycetous, saprobes, terrestrial, Europe, North America, see Seifert et al. (2011; morphology), Wijayawardene et al. (2012, 2017b, c; outline), Kirk et al. (2013; not listed), cultures and sequences are unavailable.

Sphaeropezia Sacc. 1884, Odontotremataceae, Ostropales, Lecanoromycetes, c. 20 species, type: S. alpina Sacc., asexual morph unknown, lichenized, terrestrial, cosmopolitan, see Baloch et al. (2013; resurrected the genus), Wijayawardene et al. (2017c; outline), sequences are available.

Spicularia Pers. 1822, Ascomycota genera incertae sedis, one species, type: S. simplex (Pers.) Pers., hyphomycetous, saprobes, terrestrial, Europe, America, see Seifert et al. (2011; not accepted), Wijayawardene et al. (2012, 2017b, c; outline), Kirk et al. (2013; not listed), cultures and sequences are unavailable.

Spissiomyces Lei Su, Li Y. Guo \& Xing Z. Liu 2015, Dothideomycetes, genera incertae sedis, five species, type: S. aggregatus Lei Su, Li Y. Guo \& Xing Z. Liu, hyphomycetous, sexual morph unknown, rock-inhabiting, terrestrial, China, see $\mathrm{Su}$ et al. (2015; taxonomy), taxonomy, Wijayawardene et al. (2017c; outline), cultures and sequences are available.

Sporendonema Desm. 1827, Onygenaceae, Onygenales, Eurotiomycetes, two species, type: S. casei Desm., hyphomycetous, sexual morph unknown, on cheese and fungi, terrestrial, Europe, North America, see Seifert et al. (2011; morphology), Wijayawardene et al. (2012, 2017b, c; outline), cultures and sequences are available

Stenellopsis B. Huguenin 1966, Ascomycota genera incertae sedis, five species, type: S. fagraeae B. Huguenin, hyphomycetous, saprobes, terrestrial, Asia, Australasia, see Seifert et al. (2011; not 
listed), Wijayawardene et al. (2012, 2017b, c; outline), Kirk et al. (2013; not listed), cultures and sequences are available.

Stictophacidium Rehm 1888, Stictidaceae, Ostropales, Lecanoromycetes, one species, type: S. carniolicum Rehm, asexual morph hyphomycetous, ?saprobes, Europe, see Lumbsch \& Huhndorf (2010; outline), Wijayawardene et al. (2012, 2017b, c; outline), cultures and sequences are unavailable.

Stromatinia (Boud.) Boud. 1907, Sclerotiniaceae, Helotiales, Leotiomycetes, c. 15 species, type: S. rapulum (Bull.) Boud., asexual morph unknown, saprobes, cosmopolitan, see Lumbsch \& Huhndorf (2010; outline), Kirk et al. (2013; genus accepted), Wijayawardene et al. (2017c; outline), cultures and sequences are available.

Subicularium M.L. Farr \& Goos 1989, Ascomycota genera incertae sedis, five species, type: $S$. reticulatum M.L. Farr \& Goos, hyphomycetous, saprobes, terrestrial, Venezuela, see Seifert et al. (2011; morphology), Wijayawardene et al. (2012, 2017b, c; outline), Kirk et al. (2013; not listed), cultures and sequences are available.

Sulcispora Shoemaker \& C.E. Babc. 1989, Phaeosphaeriaceae, Pleosporales, Dothideomycetes, one species, saprobes, see Kirk et al. (2013; genus accepted), Phookamsak et al. (2014; notes), Li et al. (2015; phylogeny), cultures and sequences are available.

Sultanimyces Videira \& Crous 2017, Mycosphaerellaceae, Capnodiales, Dothideomycetes, one species, type: S. vitiphyllus (Speschnew) Videira \& Crous, hyphomycetous, pathogens, terrestrial, Uzbekistan, South Africa, see Videira et al. (2017; taxonomy, phylogeny), Wijayawardene et al. (2017c; outline), cultures and sequences are available.

Sympodiosynnema J.W. Xia \& X.G. Zhang 2016, Ascomycota genera incertae sedis, one species, type: S. elegans J.W. Xia \& X.G. Zhang, hyphomycetous, saprobes, terrestrial, China, see Xia et al. (2016; taxonomy), Wijayawardene et al. (2017c; outline), cultures and sequences are available.

Teratoramularia Videira, H.D. Shin \& Crous 2016, Teratosphaeriaceae, Capnodiales, Dothideomycetes, four species, type: T. persicariae Videira, H.D. Shin \& Crous, hyphomycetous, sexual morph unknown, saprobes, terrestrial, cosmopolitan, see Videira et al. (2016; taxonomy, phylogeny), Wijayawardene et al. (2017c; outline), ex-type and holotype of the type: CBS 141105, KUS-F20536.

Thermomyces Tsikl. 1899, Trichocomaceae, Eurotiales, Eurotiomycetes, one species, type: T. lanuginosus Tsikl, six species, hyphomycetous, sexual morph unknown, worldwide, see Houbraken \& Samson (2011; phylogeny), Seifert et al. (2011; morphology), Wijayawardene et al. (2012, 2017b; outline), Kirk et al. (2013; genus accepted), cultures and sequences are available.

Toxosporium Vuill. 1896, Ascomycota genera incertae sedis, one species, type: T. abietinum Vuill., hyphomycetous, saprobes, terrestrial, Europe, North America, see Seifert et al. (2011; taxonomy), Kirk et al. (2013; genus accepted), Wijayawardene et al. (2012, 2017b, c; outline), cultures and sequences are unavailable.

Tretendophragmia Subram. 1995, Ascomycota genera incertae sedis, one species, type: $T$. palmivora Subram., hyphomycetous, saprobes, terrestrial, Europe, North America, see Seifert et al. (2011; taxonomy), Kirk et al. (2013; genus accepted), Wijayawardene et al. (2012, 2017b, c; outline), cultures and sequences are unavailable. 
Tretospora M.B. Ellis 1976, Ascomycota genera incertae sedis, eight species, type: T. negrii M.B. Ellis, hyphomycetous, sexual morph unknown, saprobes, terrestrial, Africa, Asia, see Kirk et al. (2013; not listed), Wijayawardene et al. (2017b; outline, treated as in Dothideomycetes), cultures and sequences are unavailable thus we treat as Ascomycota incertae sedis.

Trichaleurina Rehm 1903, Chorioactidaceae, Pezizales, Pezizomycetes, one species, type: T. polytricha Rehm, saprobes?, see Jaklitsch et al. (2016; classification), Wijayawardene et al. (2017c; outline), sequences are unavailable.

Tricornispora Bonar 1967, Ascomycota genera incertae sedis, one species, type: T. bambusae Bonar, hyphomycetous, on fungi, terrestrial, Asia, see Seifert et al. (2011; morphology, accepted as a distinct genus), Kirk et al. (2013; not listed), Wijayawardene et al. (2012, 2017b, c; outline), cultures and sequences are unavailable.

Vacuiphoma Valenzuela-Lopez, Cano, Crous, Guarro \& Stchigel 2017, Didymellaceae, Pleosporales, Dothideomycetes, two species, type: V. bulgarica (Aveskamp et al.) ValenzuelaLopez, Cano, Crous, Guarro \& Stchigel, coelomycetous, saprobes or pathogens, Bulgaria, USA, see Valenzuela-Lopez et al. (2017; morphology, phylogeny), Wijayawardene et al. (2017; outline), cultures and sequences are available.

Varicosporella Lechat \& J. Fourn. 2015, Nectriaceae, Hypocreales, Sordariomycetes, five species, type: V. aquatica Lechat \& J. Fourn., hyphomycetous, saprobes, aquatic, France, see Lechat \& Fournier (2015; taxonomy), Wijayawardene et al. (2017c; outline), cultures and sequences are available.

Verkleyomyces Y. Marín \& Crous 2017, Dermateaceae, Helotiales, Leotiomycetes, one species, type: V. illicii (X. Sun, L. Wang \& L.D. Guo) Y. Marín \& Crous, coelomycetous, cosmopolitan, see Marin-Felix et al. (2017; taxonomy, phylogeny), Wijayawardene et al. (2017c; outline), cultures and sequences are available.

Virosphaerella Videira \& Crous 2017, Mycosphaerellaceae, Capnodiales, Dothideomycetes, one species, type: V. pseudomarksii (Cheewangkoon et al.) Videira \& Crous, asexual morph unknown, pathogens, terrestrial, Thailand, see Videira et al. (2017; taxonomy, phylogeny), Wijayawardene et al. (2017c; outline), cultures and sequences are available.

Wilsonomyces Adask., J.M. Ogawa \& E.E. Butler 1990, Ascomycota genera incertae sedis, one species, type: W. carpophilus (Lév.) Adask., J.M. Ogawa \& E.E. Butler, hyphomycetous, saprobes, terrestrial, cosmopolitan, see Seifert et al. (2011; morphology, accepted as a distinct genus), Kirk et al. (2013; not listed), Wijayawardene et al. (2012, 2017b, c; outline), cultures and sequences are unavailable.

Xenokylindria DiCosmo, S.M. Berch \& W.B. Kendr. 1983, Ascomycota genera incertae sedis, one species, type: X. prolifera (Matsush.) DiCosmo, S.M. Berch \& W.B. Kendr., hyphomycetous, saprobes, terrestrial, cosmopolitan, see Réblová et al. (2011; notes), Seifert et al. (2011; doubtful genus), Kirk et al. (2013; not listed), Wijayawardene et al. (2012, 2017b, c; outline), cultures and sequences are unavailable.

Xenomyrothecium L. Lombard \& Crous 2016, Stachybotryaceae, Hypocreales, Sordariomycetes, one species, type: X. tongaense (W.B. Kendr., DiCosmo \& Michaelides) L. Lombard \& Crous, hyphomycetous, saprobes, terrestrial, Tonga, see Lombard et al. (2016; taxonomy), Wijayawardene et al. (2017c; outline), cultures and sequences are available. 
Xenopyrenochaetopsis Valenzuela-Lopez, Crous, Stchigel, Guarro \& Cano 2017, Pyrenochaetopsidaceae, Pleosporales, Dothideomycetes, one species, type: X. pratorum (P.R. Johnst. \& Boerema) Valenzuela-Lopez, Crous, Stchigel, Guarro \& Cano, coelomycetous, saprobes, New Zealand, see Valenzuela-Lopez et al. (2017; morphology, phylogeny), Wijayawardene et al. (2017; outline), cultures and sequences are available.

Xenosonderhenioides Videira \& Crous 2017, Mycosphaerellaceae, Capnodiales, Dothideomycetes, one species, type: $V$. indonesiana C. Nakash., Videira \& Crous, hyphomycetous, pathogens, terrestrial, Indonesia, see Videira et al. (2017; taxonomy, phylogeny), Wijayawardene et al. (2017c; outline), cultures and sequences are available.

Yunnania H.Z. Kong 1998, Microascaceae, Microascales, Sordariomycetes, three species, type: $Y$. penicillata H.Z. Kong, hyphomycetous, cosmopolitan, see Houbraken \& Samson (2011; phylogeny), Seifert et al. (2011; treated as a synonym of Penicillium), Wijayawardene et al. (2017c; outline), cultures and sequences are available.

\section{Acknowledgements}

This study was jointly funded by the Youth Research Fund of Shandong Academy of Agricultural Sciences (2016YQN32), the Science and Technology Program of Tai'an, China (2017NS0093). We would like to thank D.L. Hawksworth and T.H. Lumbsch who provided comments on lichen genera. KC Rajeshkumar thanks Dr. K.M. Paknikar, Director, ARI for providing the facilities.

\section{References}

Abdel-Wahab MA, Dayarathne MC, Suetrong S, Guo SY et al. 2017 - New saprobic marine fungi and a new combination. Botanica Marina 60, 469-488

Baloch E, Gilenstam G, Wedin M. 2013 - The relationships of Odontotrema (Odontotremataceae) and the resurrected Sphaeropezia (Stictidaceae) - new combinations and three new Sphaeropezia species. Mycologia 105, 384-397

Chen C, Verkley GJ, Sun G, Groenewald JZ et al. 2016 - Redefining common endophytes and plant pathogens in Neofabraea, Pezicula, and related genera. Fungal Biology 120, 1291-1322

Crane JL, Miller AN. 2016 - Studies in genera similar to Torula: Bahusaganda, Bahusandhika, Pseudotorula, and Simmonsiella gen. nov. IMA fungus 7, 29-45

Crous PW, Braun U, Hunter GC, Wingfield MJ et al. 2012 - Phylogenetic lineages in Pseudocercospora. Studies in Mycology 75, 37-114

De Beer ZW, Duong TA, Wingfield MJ. 2016a - The divorce of Sporothrix and Ophiostoma: solution to a problematic relationship. Studies in Mycology 83, 165-191

De Beer ZW, Marincowitz S, Duong TA, Kim JJ et al. 2016b - Hawksworthiomyces gen. nov. (Ophiostomatales), illustrates the urgency for a decision on how to name novel taxa known only from environmental nucleic acid sequences (ENAS). Fungal Biology 120, 1323-1340

de Gruyter J, Woudenberg JHC, Aveskamp MM, Verkley GJM et al. 2012 - Redisposition of Phoma-like anamorphs in Pleosporales. Studies in Mycology 75, 1-36

Delgado G, Miller AN, Fernández FA 2015 - Curviclavula, a new genus of anamorphic Helotiales (Leotiomycetes) isolated from air. Mycological Progress 14, 3 DOI 10.1007/s11557-0151025-3

Divakar PK, Crespo A, Kraichak E, Leavitt SD et al. 2017 - Using a temporal phylogenetic method to harmonize family-and genus level classification in the largest clade of lichen-forming fungi. Fungal Diversity 84, 101-117

Ekanayaka AH, Ariyawansa HA, Hyde KD, Jones EB et al. 2017 - Discomycetes: the apothecial representatives of the phylum Ascomycota. Fungal Diversity 87, 237-298 
Fernandez-Lafuente R. 2010 - Lipase from Thermomyces lanuginosus: uses and prospects as an industrial biocatalyst. Journal of Molecular Catalysis B: Enzymatic 62, 197-212.

Gams W, Seifert KA, Morgan-Jones G. 2009 - New and validated hyphomycete taxa to resolve nomenclatural and taxonomic issues. Mycotaxon 110, 89-108

Gao L, Wei Z, Wang B, Gleason ML et al. 2015 - A new species of Scleroramularia associated with sooty blotch and flyspeck in Southern China. Phytotaxa 226, 261-268

González CD, Chaverri P 2017 - Corinectria, a new genus to accommodate Neonectria fuckeliana and $C$. constricta sp. nov. from Pinus radiata in Chile. Mycological Progress 16, 1015- 1027

Hafellner J, Rogers RW. 1990 - Maronina, a new genus of lichenised ascomycetes (Lecanorales, Lecanoraceae) with multispored asci. Bibliotheca Lichenologica 38, 99-108

Hernández-Restrepo M, Groenewald JZ, Elliott ML, Canning G et al. 2016 - Take-all or nothing. Studies in Mycology 83, 19-48

Hongsanan S, Maharachchikumbura SS, Hyde KD, Samarakoon MC et al 2017 - An updated phylogeny of Sordariomycetes based on phylogenetic and molecular clock evidence. Fungal Diversity 84, 25-41

Houbraken J, Samson RA. 2011 - Phylogeny of Penicillium and the segregation of Trichocomaceae into three families. Studies in Mycology 70, 1-51

Hyde KD, Jones EBG, Liu JK, Ariyawansa H et al. 2013 - Families of Dothideomycetes. Fungal Diversity 63, 1-313

Hyde KD, McKenzie EHC, Koko TW. 2011 - Towards incorporating anamorphic fungi in a natural classification - checklist and notes for 2010. Mycosphere 2, 1-88

Hyde KD, Maharachchikumbura SS, Hongsanan S, Samarakoon MC et al. 2017 - The ranking of fungi: a tribute to David L. Hawksworth on his 70th birthday. Fungal Divers 84, 1-23

Index Fungorum (2017) http://www.indexfungorum.org. Accessed in December 2017

Index Fungorum (2018) http://www.indexfungorum.org. Accessed in January 2018

Jaklitsch W, Baral HO, Lücking R, Lumbsch HT. 2016 - Ascomycota. In: Frey W (ed) Syllabus of Plant Families, $23^{\text {rd }}$ edn. Borntraeger Science Publishers, Stuttgart

Jaklitsch WM, Voglmayr H. 2017 - Three former taxa of Cucurbitaria and considerations on Petrakia in the Melanommataceae. Sydowia 69, 81-95

Johnston PR, Rogers JD, Park D, Martin NA. 2016 - Entalbostroma erumpens gen. et sp. nov. (Xylariaceae) from Phormium in New Zealand. Mycotaxon 131, 765-771

Kirk PM, Cannon PF, Minter DW, Stalpers JA. 2008 - Ainsworth \& Bisby's Dictionary of the Fungi, 10th edn. CAB International, Wallingford.

Kirk PM, Stalpers JA, Braun U, Crous PW et al. 2013 - A without prejudice list of generic names of fungi for protection under the International Code of Nomenclature for algae, fungi, and plants. IMA fungus 4, 381-443

Kirschner R, Pang KL, Jones EG. 2013 - Two cheirosporous hyphomycetes reassessed based on morphological and molecular examination. Mycological Progress 12, 29-36

Kiyuna T, An KD, Kigawa R, Sano C et al. 2012 - Bristle-like fungal colonizers on the stone walls of the Kitora and Takamatsuzuka Tumuli are identified as Kendrickiella phycomyces. Mycoscience 53, 446-459

Koukol O, Hofmann TA, Piepenbring M. 2017 - Dendroseptoria mucilaginosa: a new anamorphic fungus with stauroconidia and phylogenetic placement of Dendroseptoria. Mycol Progress https://doi.org/10.1007/s11557-017-1351-8

Lechat C, Fournier J 2015 - Varicosporella, a new aquatic genus in the Nectriaceae from France. Ascomycete. org. 7, 1-8

Li H, Sun G, Batzer JC, Crous PW 2011 - Scleroramularia gen. nov. associated with sooty blotch and flyspeck of apple and pawpaw from the Northern Hemisphere. Fungal Diversity 46, 53-66

Li WJ, Bhat DJ, Camporesi E, Tian Q, Wijayawardene NN et al. 2015 - New asexual morph taxa in Phaeosphaeriaceae. Mycosphere 6, 681-708 
Liu JK, Hyde KD, Jeewon R, Phillips AJL et al 2017 - Ranking higher taxa using divergence times: a case study in Dothideomycetes. Fungal Diversity 84, 75-99

Lombard L, Houbraken J, Decock C, Samson RA et al. 2016 - Generic hyper-diversity in Stachybotriaceae. Persoonia 36, 156-246

Lücking R, Hodkinson BP, Leavitt SD. 2017 - The 2016 classification of lichenized fungi in the Ascomycota and Basidiomycota-approaching one thousand genera. Bryologist 119, 361-416

Lumbsch HT, Huhndorf SM 2010 - Outline of Ascomycota 2009. Myconet 14, 1-64

Luo J, Walsh E, Naik A, Zhuang W et al. 2014a - Temperate pine barrens and tropical rain forests are both rich in undescribed fungi. PloS one 9, e103753

Luo J, Walsh E, Zhang N 2014b - Four new species in Magnaporthaceae from grass roots in New Jersey Pine Barrens. Mycologia 106, 580-588

Luo J, Walsh E, Blystone D, Zhang N 2015a - Five new Pseudophialophora species from grass roots in the oligotrophic pine barrens ecosystem. Fungal Biology 119, 1205-1215

Luo J, Walsh E, Zhang N. 2015b - Toward monophyletic generic concepts in Magnaporthales: species with Harpophora asexual states. Mycologia 107, 641-646

Maharachchikumbura SSN, Hyde KD, Jones EBG, McKenzie EHC et al 2015 - Towards a natural classification and backbone tree for Sordariomycetes. Fungal Divers 72, 199-301

Maharachchikumbura SSN, Hyde KD, Jones EBG, McKenzie EHC et al 2016 - Families of Sordariomycetes. Fungal Diversity 79, 1-317

Marin-Felix Y, Groenewald JZ, Cai L, Chen Q et al. 2017 - Genera of phytopathogenic fungi: GOPHY 1. Studies in Mycology 86, 99-216

Mel'nik VA. 2012 - A new species of Ardhachandra (hyphomycetes) from Vietnam. Mycosphere 3, 922-924

Miadlikowska J, Kauff F, Högnabba F, Oliver JC et al. 2014 - A multigene phylogenetic synthesis for the class Lecanoromycetes (Ascomycota): 1307 fungi representing 1139 infrageneric taxa, 317 genera and 66 families. Molecular Phylogenetics and Evolution 79, 132-168

Papizadeh M, Wijayawardene NN, Amoozegar MA, Saba F et al. 2017 - Neocamarosporium jorjanensis, $N$. persepolisi, and N. solicola spp. nov. (Neocamarosporiaceae, Pleosporales) isolated from saline lakes of Iran indicate the possible halotolerant nature for the genus. Mycological Progress https://doi.org/10.1007/s11557-017-1341-X

Papong K, Kantvilas G, Lumbsch HT. 2011 - Morphological and molecular evidence places Maronina into synonymy with Protoparmelia (Ascomycota: Lecanorales). Lichenologist 43, 561-567

Phookamsak R, Liu JK, McKenzie EH, Manamgoda DS et al. 2014 - Revision of Phaeosphaeriaceae. Fungal Diversity 68:159-238

Randlane T, Saag A, Thell A, Ahti T. 2013 - Third world list of cetrarioid lichens-In a new databased form, with amended phylogenetic and type information. Cryptogamie Mycologie 34, 79-94

Rashmi D. 2014 - First report of Ardhachandra critaspora (Matsush.) Subram. \& Sudha on Leea indica (Burm. f.) Merr. and Syzygium cumini Skeels. Lam. from Western Ghats, India. Journal on New Biological Reports 3, 1-3

Réblová M, Gams W, Seifert KA. 2011 - Monilochaetes and allied genera of the Glomerellales, and a reconsideration of families in the Microascales. Studies in Mycology 68, 163-191

Rossman AY, Allen WC, Castlebury LA. 2016 - New combinations of plant-associated fungi resulting from the change to one name for fungi. IMA fungus $7,1-7$

Ruibal C, Gueidan C, Selbmann L, Gorbushina AA et al. 2009 - Phylogeny of rock-inhabiting fungi related to Dothideomycetes. Studies in Mycology 64,123-133

Seifert KA, Morgan-Jones G, Gams W, Kendrick B. 2011 - The genera of Hyphomycetes. CBS Biodiversity Series 9, CBSKNAW Fungal Biodiversity Centre, Utrecht

Senanayake IC, Maharachchikumbura SSN, Hyde KD, Bhat JD et al 2015 - Towards unraveling relationships in Xylariomycetidae (Sordariomycetes). Fungal Diversity 73, 73-144 
Sodamuk M, Boonpragob K, Mongkolsuk P, Tehler A et al. 2017 - Kalbionora palaeotropica, a new genus and species from coastal forests in Southeast Asia and Australia (Malmideaceae, Ascomycota). MycoKeys 22, 15-25

Su L, Guo L, Hao Y, Xiang M et al. 2015 - Rupestriomyces and Spissiomyces, two new genera of rock-inhabiting fungi from China. Mycologia 107, 831-844

Thambugala KM, Ariyawansa HA, Li YM, Boonmee S et al. 2014 - Dothideales. Fungal Diversity $68,105-158$

Thambugala KM, Daranagama DA, Phillips AJ, Bulgakov TS et al. 2017 - Microfungi on Tamarix. Fungal Diversity 82, 239-306

Thell A, Högnabba F, Elix JA, Feuerer T et al. 2009 - Phylogeny of the cetrarioid core (Parmeliaceae) based on five genetic markers. Lichenologist 41, 489-511

Trakunyingcharoen T, Lombard L, Groenewald JZ, Cheewangkoon R et al. 2014 - Mycoparasitic species of Sphaerellopsis, and allied lichenicolous and other genera. IMA fungus 5, 391-414

Tsuneda A, Davey ML, Hambleton S, Currah RS. 2008 - Endosporium, a new endoconidial genus allied to the Myriangiales. Botany 86, 1020-1033

Tsuneda A, Davey ML, Tsuneda I, Currah RS. 2010 - Two new dothideomycetous endoconidial genera from declining larch. Botany 88, 471-487

Valenzuela-Lopez N, Cano-Lira JF, Guarro J, Sutton DA et al. 2017 - Coelomycetous Dothideomycetes with emphasis on the families Cucurbitariaceae and Didymellaceae. Studies in Mycology 90, 1-69

Van Vooren N, Lindemann U, Healy R 2017 - Emendation of the genus Tricharina (Pezizales) based on phylogenetic, morphological and ecological data. Ascomycete. org 9, 101-123

Van Vooren N, Tello S, Vega M. 2015 - Pseudotricharina intermedia (Pezizales), a new genus and a new species discovered in the Mediterranean area. Ascomycete. org. 7, 341-346

Videira SI, Groenewald JZ, Nakashima C, Braun U et al. 2017 - Mycosphaerellaceae-Chaos or clarity? Studies in Mycology 87, 257-421

Voglmayr H, Friebes G, Gardiennet A, Jaklitsch WM. 2017 - Barrmaelia and Entosordaria in Barrmaeliaceae (fam. nov., Xylariales) and critical notes on Anthostomella-like genera based on multigene phylogenies. Mycological Progress https://doi.org/10.1007/s11557-017-1329-6

Wanasinghe DN, Hyde KD, Jeewon R, Crous PW et al. 2017 - Phylogenetic revision of Camarosporium (Pleosporineae, Dothideomycetes) and allied genera. Studies in Mycology 87, 207-256

Wanasinghe DN, Jones EBG, Camporesi E, Dissanayake AJ et al. 2016 - Taxonomy and phylogeny of Laburnicola gen. nov. and Paramassariosphaeria gen. nov. (Didymosphaeriaceae, Massarineae, Pleosporales). Fungal Biology 120, 1354-1373

Wang XW, Houbraken J, Groenewald JZ, Meijer M. 2016 - Diversity and taxonomy of Chaetomium and chaetomium-like fungi from indoor environments. Studies in Mycology 84, $145-224$

Wei X, Schmitt I, Hodkinson B, Flakus A et al. 2017 - Circumscription of the genus Lepra, a recently resurrected genus to accommodate the "Variolaria"-group of Pertusaria sensu lato (Pertusariales, Ascomycota). PloS one 12, e0180284

Werner RG. 1932 - Contribution á la flore cryptogamique du Maroc V. Cavanillesia 5, 157-174

Wijayawardene DNN, McKenzie EHC, Hyde KD 2012 - Towards incorporating anamorphic fungi in a natural classification - checklist and notes for 2011. Mycosphere 3, 157-228

Wijayawardene NN, Crous PW, Kirk PM, Hawksworth DL et al. 2014c - Naming and outline of Dothideomycetes-2014 including proposals for the protection or suppression of generic names. Fungal Diversity 69, 1-55

Wijayawardene NN, Hyde KD, Lumbsch HT, Liu JK et al. 2017c - Outline of Ascomycota - 2017. Fungal Diversity https://doi.org/10.1007/s13225-018-0394-8

Wijayawardene NN, Hyde KD, Rajeshkumar KC, Hawksworth DL et al. 2017a - Notes for genera: Ascomycota. Fungal Diversity 86, 1- 594 
Wijayawardene NN, Hyde KD, Tibpromma S, Wanasinghe DN et al. 2017b - Towards incorporating asexual fungi in a natural classification: checklist and notes 2012-2016. Mycosphere 8, 1457-1554

Wijayawardene NN, Hyde KD, Wanasinghe DN, Papizadeh M et al. 2016 - Taxonomy and phylogeny of dematiaceous coelomycetes. Fungal Diversity 77, 1-316

Xia JW, Ma YR, Gao JM, Li Z et al. 2016 - Sympodiosynnema, a new genus of dematiaceous hyphomycetes from southern China. Mycotaxon 131, 45-48

Zakeri Z, Divakar PK, Otte V. 2017 - Taxonomy and phylogeny of Aspiciliella, a resurrected genus of Megasporaceae, including the new species A. portosantana. Herzogia 30, 166-176

Zhang T, Deng X, Yu Y, Zhang M et al. 2016 - Pseudochaetosphaeronema ginkgonis sp. nov., an endophyte isolated from Ginkgo biloba. International Journal of Systematic and Evolutionary Microbiology 66, 4377-4381 